\title{
The Economic Content of Interest Rates, Monetary Policy and Time-Varying Risk Premia
}

\author{
Francisco Palomino* \\ Preliminary and Incomplete.
}

December 21, 2007

\begin{abstract}
The term structure of interest rates is a rich source of economic information and thus can be a powerful tool for policy making. However, this information is difficult to extract given its dependence on the actual policy regime and the existence of time-varying term premia. This paper provides an analysis of the economic content of interest rates when term premia vary over time and monetary policy is optimal. The analysis is complemented with a potentially welfare-improving application for policy making: the formulation of optimal policy rules based on term-structure information. The analysis is conducted for policies with high or low weights on inflation stabilization. It shows that a high inflation weight increases the compensation for real risks in the term structure. As a result, forward rates are less informative about expected future monetary policy, and the term spreads and short-term rate predict better real economic activity and inflation, respectively. In addition, the optimal responses in an interest-rate rule to the lagged short-rate and term spreads decline.
\end{abstract}

JEL Classification: D51, E43, E52, G12.

*Ross School of Business, The University of Michigan, fpal@bus.umich.edu. 


\section{Introduction}

The term structure of interest rates is a rich source of economic information. Forward-looking market participants implement their investment and savings decisions by trading default-free government bonds for a wide spectrum of maturities. As a result, interest rates (bond prices) must reflect these decisions and contain current and expected future economic conditions for different time horizons. Then, the term structure is potentially useful for policy makers to predict the future state of the economy and obtain market expectations about future policies. ${ }^{1}$ This task is far from trivial and demands an underlying economic theory of the term structure. ${ }^{2}$

Most of the analysis of the economic content of interest rates has been conducted assuming the validity of the theory of the expectations hypothesis. ${ }^{3}$ This theory simplifies the interpretation of the content of long-term interest rates since all variation in long-term rates must reflect changes in expectations of future short-term rates. Unfortunately, numerous studies such as Fama and Bliss (1987) or Campbell and Shiller (1991) provide empirical evidence rejecting this theory and shed doubts about the validity of its implications. Alternatively, Duffee (2002) and Dai and Singleton (2002) show that time-varying term premia provide a better description of the observed properties of interest rates. This finding suggests that, in order to properly extract information from the term structure, it is important to understand the sources of time variation in risk premia. This is not a simple task in the absence of a model that simultaneously captures macroeconomic behavior and asset-pricing properties. In addition, the analysis becomes more complicated if one of the purposes is to answer policy-related questions. It is the case since different policies may have different effects on the properties and economic content of interest rates.

This paper explores the economic content of long-term interest rates when time-varying term premia and optimal monetary policy are taken into consideration. It analyzes the extraction from interest rates of expectations about future monetary policy and current and expected future macroeconomic conditions. It also examines the implementation of monetary policy with policy rules that react to the term structure. Additionally, it allows welfare interpretations for changes in the content of interest rates that are related to changes in the objective of monetary policy.

The framework for the analysis is a general equilibrium model that links economic activity to monetary policy and the term structure of interest rates. Monetary policy has real economic effects and is conducted under discretion by a social planner that assigns weights to inflation and output stabilization. The purpose of the policy is to minimize, given these weights, deviations

\footnotetext{
${ }^{1}$ See Goodfriend (1998) for potential applications of the term structure for monetary policy.

${ }^{2}$ See the remarks of the chairman of the Federal Reserve Ben Bernanke before the Economic Club of New York, March 20, 2006. They provide an idea of some of the difficulties faced by policy makers in extracting information from the yield curve.

${ }^{3}$ See for instance Estrella and Hardouvelis (1991) or Estrella (2005).
} 
from output and inflation targets in a policy function. Depending on the policy, risk premia vary over time as a result of preference shocks in the households' utility that are sensitive to lagged aggregate consumption. The equilibrium interest rates and term premia for all maturities can be expressed as affine functions of macroeconomic variables. This feature provides a direct link between economic conditions and interest rates and greatly simplifies the analysis of the economic content of the term structure. In order to understand this content, the model is calibrated and a policy experiment with welfare interpretations is performed. The experiment consists in reducing the weight of inflation in the policy function. Clarida, Galí and Gertler (1999) show that certain policies under commitment can be implemented under discretion by increasing the weight of inflation in the policy function. Given that optimal policies under commitment involve welfare benefits over policies under discretion, the reduction of the inflation weight in the policy experiment can be seen as a policy-motivated reduction in economic welfare.

The weight of inflation in the policy function has a considerable impact on the behavior of interest rates. This weight determines the stability of real activity and inflation around their targets. In particular, a policy that assigns a high weight to inflation allows for greater instability in output and thus increases the proportion of real risks to nominal risks. As a result, market participants demand higher compensations for financial assets that are exposed to real risks and then, the economic content of nominal interest rates is significantly affected.

The existence of time-varying term premia has important implications for the content of the yield curve. For instance, it is not possible to extract expectations about future short rates from forward rates directly. One-period forward rates do not only contain expectations about the oneperiod short rate over time. They also embed compensations for risk that depend on the state of the economy and monetary policy. The analysis shows that depending on the type of shock that hits the economy (demand or supply), the risk premia component in forward rates can vary significantly. Specifically, the impact is high when a demand shock affects an economy where the inflation weight in the policy objective is high. Assuming that monetary policy is implemented using the short-term nominal rate as instrument, this variation represents a considerable challenge for policy makers who want to extract expected paths for monetary policy from interest rates. In that case, this paper shows that they can complement forward rates with the current level of the short-term rate and lagged macroeconomic information to obtain better forecasts of future monetary policy.

The information of interest rates about current and future macroeconomic conditions is also affected by the existence of time-varying term premia. For instance, expected inflation can not be obtained as the difference between nominal and real rates. This difference also captures a risk premium component due to the correlation between real activity and inflation. The size of 
this component and its responses to uncertainty are determined by monetary policy. It is shown that this component varies significantly with supply shocks if the inflation weight in the policy objective function is high. More generally, this paper also contains an analysis of the predictive power of interest rates for future consumption growth and inflation at different horizons. It shows that while the information of interest-rate spreads about future consumption growth is low in comparison to the information of the short-term rate, spreads have an important predictive power for future inflation. In addition, this paper shows how to extract current macroeconomic information from term-structure information.

The analysis is complemented with a potential application for the implementation of optimal monetary policy. The application is the formulation of short-term interest-rate policy rules that react to the term structure. In practice, the implementation of macroeconomic-based policy rules is limited by the availability and quality of macroeconomic information. For instance, Taylor (1993) proposes an interest-rate rule where the Fed's operating target is a function of current inflation and deviations of real GDP from "potential output". However, at the time the operating target is chosen, the current inflation rate and the GDP figures have not been released and must be forecast using alternative indicators. Orphanides (2001) shows that policy recommendations based on these indicators differ considerably from those obtained with the ex post revised data. As a result, these recommendations may lead to inappropriate policy outcomes. On this ground, McCallum (1999) criticizes the Taylor rule for not being operational and proposes to focus on rules that explicitly specify the operating target as a function of data available to the policy maker at the time the target decision is made. Since bond prices are available on real-time, long-term interest rates embed informational advantages over macroeconomic data which can be exploited through a term-structure-based policy rule.

The fact that the equilibrium term structure is affine allows a simple evaluation of several types of interest-rate rules. The short-term rate can be written as a linear combination of contemporaneous and lagged variables. These variables can be macroeconomic variables or interest rate levels and spreads. Specifically, three different types of rules are analyzed: (i) a term structure rule, (ii) a macro and term structure rule and (iii) a rule with interest rate smoothing. The term structure rule is useful to determine how the short-term rate should react to different sectors of the curve. It is found that this rule involve negative reaction to the short and long term spreads of the curve and a positive response to intermediate maturity spreads. Also, the sensitivity of the rule to term spreads increases with the inflation weight in the policy objective. The macro and term structure rules are helpful to determine which sectors of the curve provide information that is not contained in a particular macro variable. A policy with high weight on inflation imply high reactions to both macro and term structure variables. Finally, the analysis of policy rules with interest rate smoothing show that the smoothing coefficient increases with the maturity of the 
spread that is used in the rule and decreases with the weight of inflation in the policy objective function.

The rest of the paper is organized as follows. Section 2 explains the economic model and the equilibrium affine term structure. Section 3 develops the analysis and presents the calibration and policy experiment. Section 4 concludes and the Appendix contains useful mathematical derivations and calibration details.

\section{The Model}

This section presents the economic model that is used for the joint analysis of monetary policy and the term structure of interest rates. The framework is a standard dynamic general equilibrium model for the analysis of monetary policy as presented in Clarida, Galí and Gertler (1999) or Woodford (2003), extended to capture long-term interest rate properties. In particular, monetary policy is conducted optimally in the model economy and the equilibrium term structure of interest rates is affine with time-varying term premia. This model links the behavior of interest rates to the objective of monetary policy and macroeconomic conditions. As a result, the model allows us to understand the implications of monetary policy on interest rates and thus to analyze the economic content of the term structure.

\subsection{Optimal Monetary Policy}

The monetary authority in the economy can be seen as a social planner that chooses optimal contingent paths for output, inflation and a nominal interest rate to maximize welfare. The maximization problem is constrained by conditions that characterize the optimal behavior of the private sector (households and firms) and, therefore, must be satisfied in equilibrium. Firms are monopolistic competitor suppliers of multiple goods in an environment where nominal prices are not perfectly flexible. This friction allows monetary policy to have effects on the real economy. We abstract from investment and capital accumulation and thus the equilibrium output is equal to aggregate consumption.

Let $c_{t} \equiv \log C_{t}$ be the level of consumption (output) in logarithmic terms and $\pi_{t}$ be the deviation of the inflation rate from its long-run level. It is convenient to define the difference between actual consumption and the consumption that would be observed if prices were perfectly flexible $\left(c_{t}^{n a t} \equiv \log C_{t}^{n a t}\right)$. This difference is known as the "output gap"

$$
x_{t} \equiv c_{t}-c_{t}^{n a t} .
$$


In addition, let $i_{t}$ be the one-period nominal interest rate that is determined by the monetary policy. Using this notation, the monetary policy problem can be written as

$$
\min _{\left\{\pi_{t}, x_{t}, i_{t}\right\}} \mathbb{E}\left\{\sum_{t=0}^{\infty} \beta^{t}\left[\rho \pi_{t}^{2}+\kappa\left(x_{t}-x^{*}\right)^{2}\right]\right\}
$$

subject to

$$
e^{-i_{t}}=\mathbb{E}_{t}\left[M_{t, t+1}\right]
$$

and

$$
\pi_{t}=\kappa x_{t}+\beta \mathbb{E}_{t} \pi_{t+1}+\epsilon_{t},
$$

where $\beta$ is the subjective discount factor. The objective function (2) describes a welfare measure where deviations of the output gap from the target $x^{*}$ reduce welfare as well as deviations of inflation from a zero target. The parameters $\rho$ and $\kappa$ are the relative weights assigned to inflation and output deviations, respectively. Rotemberg and Woodford (1999) show that the objective function can be obtained from a quadratic approximation of the utility function. We do not restrict here the objective function to be the utility function for the economy presented in subsection 2.2 below. This flexibility allows us to analyze policies where the monetary authority is more or less conservative about inflation than what the utility-based welfare measure prescribes.

Equation (3) is the optimality condition for the household problem that relates the price of a one-period nominal bond to the one-period marginal rate of substitution of consumption, $M_{t, t+1}$. The characterization of the marginal rate plays a fundamental role capturing interest rate properties and is presented in subsection 2.2 .

The aggregate supply equation (4) describes the optimality condition for the profit maximization problem of monopolistic competitor suppliers of multiple goods. The staggered price setting generates a short-run relation between inflation and the output gap that is captured by the parameter $\kappa$. Simultaneously, given the forward-looking nature of economic agents, the current level of inflation is affected by expectations about future inflation. An important component to capture time variation in inflation is the cost-push shock $\epsilon_{t}$. This shock can be interpreted as a markup shock or, more general, a deviation breaking the proportionality between marginal costs and the output gap. We assume that the cost-push shock follows the process

$$
\epsilon_{t+1}=\phi_{\epsilon} \epsilon_{t}+\sigma_{\epsilon} \varepsilon_{\epsilon, t+1}
$$

where $\varepsilon_{\epsilon, t} \sim \operatorname{IID} \mathcal{N}(0,1)$. 
The monetary authority solves the policy problem under discretion. That is, it re-optimizes every period and takes the expectations of the private sector as given. Under this assumption the optimality condition for the problem above becomes ${ }^{4}$

$$
x_{t}-x^{*}=-\rho \pi_{t}
$$

This equation can be seen as a targeting rule for inflation. It tells us that the optimal policy under discretion involves a tradeoff between deviations from the target output gap and inflation. The tradeoff depends on the relative weight of inflation in the policy objective function (2). A higher inflation weight allows more deviations in the output gap.

From the optimality condition above and equation (4) we can write the output gap in terms of inflation and obtain a rational expectations equation in terms of the endogenous inflation and the exogenous cost-push shock. It can be shown that the equilibrium inflation process can be written as

$$
\pi_{t}=\delta_{\pi}+\delta_{\epsilon} \epsilon_{t}
$$

where the inflation bias and the sensitivity of inflation to the cost-push shock are, respectively,

$$
\delta_{\pi}=\frac{\kappa x^{*}}{1-\beta+\rho \kappa} \quad \text { and } \quad \delta_{\epsilon}=\frac{1}{1-\beta \phi_{\epsilon}+\rho \kappa} .
$$

The inflation bias $\delta_{\pi}$ arises when the output gap target is not zero. ${ }^{5}$ It is also clear that the sensitivity of inflation to cost-push shocks and the inflation bias are lower when the monetary authority is more conservative about inflation (high $\rho$ ).

Given the assumed process for the cost-push shock, the inflation process can also be written as the autoregressive process

$$
\pi_{t+1}=\left(1-\phi_{\epsilon}\right) \delta_{\pi}+\phi_{\epsilon} \pi_{t}+\delta_{\epsilon} \sigma_{\epsilon} \varepsilon_{\epsilon, t+1}
$$

showing that equilibrium inflation inherits the persistence of the cost-push shock regardless of the relative weight $\rho$.

By replacing the equilibrium processes for consumption and inflation into equation (3) we obtain the equilibrium one-period interest rate in terms of the marginal rate of substitution of consumption $M_{t, t+1}$. This rate is characterized in the next subsection.

\footnotetext{
${ }^{4}$ Notice that the short-term interest rate equation (3) does not play a role in determining the optimality condition, given that the objective function does not depend on this interest rate.

${ }^{5}$ A utility-based welfare function implies $\left(x^{*} \neq 0\right)$ when the natural rate of consumption is not efficient.
} 


\subsection{The Marginal Rate of Substitution of Consumption}

We derive the intertemporal marginal rate of substitution of consumption following the specification in Gallmeyer, Hollifield and Zin (2005) for the utility derived by households from consumption. ${ }^{6}$ This utility is given by

$$
\sum_{t=0}^{\infty} \beta^{t} \frac{C_{t}^{1-\gamma}}{1-\gamma} Q_{t},
$$

with $\gamma$ capturing local risk aversion. This representation differs from the standard relative risk aversion setting in that it incorporates the preference shock $Q_{t}$. The process for the shock $q_{t} \equiv \log Q_{t}$ is

$$
-\Delta q_{t+1}=\frac{1}{2} \eta^{2} \Delta c_{t}^{2} \operatorname{var}_{t}\left(\Delta c_{t+1}\right)+\eta \Delta c_{t}\left(\Delta c_{t+1}-\mathbb{E}_{t} \Delta c_{t+1}\right),
$$

which potentially allows for risk aversion that changes over time. The parameter $\eta$ is the sensitivity of the shock to unexpected consumption growth per unit of lagged consumption growth. Given the dependence on lagged aggregate consumption, the preference shock can also be interpreted as an external habit. The quadratic term on $\Delta c_{t}$ is a correction term that makes $Q_{t}=\mathbb{E}_{t}\left[Q_{t+1}\right]$ and preserves the affine framework for the equilibrium term structure as shown in subsection 2.3.

By solving the household utility maximization problem we obtain the intertemporal marginal rate of substitution of consumption between periods $t$ and $t+n, M_{t, t+n}$, given by

$$
M_{t, t+n}=\beta^{n}\left(\frac{C_{t+n}}{C_{t}}\right)^{\gamma}\left(\frac{Q_{t+n}}{Q_{t}}\right)\left(\frac{P_{t+n}}{P_{t}}\right) .
$$

Additionally, the household problem provides us with the no-arbitrage price for nominal bonds. The price of an $n$-period default free bond $b_{t}^{(n)}$ is

$$
b_{t}^{(n)}=\mathbb{E}_{t}\left[M_{t, t+n}\right]
$$

and the associated continuously-compounded interest rate is

$$
i_{t}^{(n)}=-\frac{1}{n} \log b_{t}^{(n)}
$$

Therefore, the constraint (3) in the policy problem can be seen as a particular case of equation (9) when $n=1$. This equation becomes

$$
e^{-i_{t}}=\mathbb{E}_{t}\left[\exp \left(\log \beta-\gamma \Delta c_{t+1}+\Delta q_{t+1}-\pi_{t+1}-\theta_{\pi}\right)\right]
$$

where $\theta_{\pi}=\log \left(P_{t+1} / P_{t}\right)-\pi_{t+1}$ is the inflation trend.

\footnotetext{
${ }^{6}$ Based on the assumption that consumption and labor are separable in the utility function, we do not need to specify preferences for labor to obtain the marginal rate of substitution of consumption.
} 
Equation (10) tells us that the equilibrium one-period interest rate $i_{t}$ depends on the processes for consumption growth and inflation. Differencing equation (1), consumption growth is given by the natural rate of consumption growth and changes in the output gap. From the target rule (5) we find that changes in the output gap are given by $\Delta x_{t}=-\rho \Delta \pi_{t}$ and thus the consumption growth process is

$$
\Delta c_{t}=\Delta c_{t}^{n a t}-\rho \Delta \pi_{t}
$$

where the equilibrium inflation is found from equation (6). Thus, the consumption growth process under the optimal discretionary policy is negatively affected by positive changes in inflation and the effect is amplified when the monetary authority is more conservative about inflation.

In order to obtain a complete characterization of consumption growth, we assume that the natural rate of consumption growth $\Delta c_{t}^{n a t}$ is not affected by monetary policy and define the exogenous process

$$
\Delta c_{t+1}^{n a t}=\left(1-\phi_{c}\right) \theta_{c}+\phi_{c} \Delta c_{t}^{n a t}+\sigma_{c} \varepsilon_{c, t+1},
$$

where $\varepsilon_{c, t} \sim \operatorname{IID} \mathcal{N}(0,1)$.

\subsection{The Term Structure of Interest Rates}

Bond prices and long-term interest rates for different maturities are obtained from the equilibrium equations (8) and (9) in terms of deep economic paramaters such as preference, production and policy parameters. This representation is useful to understand the link between macroeconomic activity, monetary policy and long-term interest rates. This subsection shows that the equilibrium interest rates can be described by using a discrete-time version of the Duffie and Kan (1996) affine class of arbitrage-free term-structure models, where interest rates can be expressed as linear combinations of some state variables. ${ }^{7}$ One of the advantages of this framework is the possibility to compare interest rates for different maturities in terms of exposures to a reduced set of state variables. We describe first the general affine framework and then we present the restrictions on the parameters imposed by the equilibrium term structure in the economic model.

Consider the $k$-dimensional vector of state variables $\mathbf{s}_{t}$, following the first-order vector autoregression

$$
\mathbf{s}_{t+1}=(\mathbb{I}-\Phi) \theta+\Phi \mathbf{s}_{t}+\Psi^{\top} \Sigma^{1 / 2} \varepsilon_{t+1}
$$

where $\mathbb{I}$ is the $k \times k$ identity matrix and $\varepsilon_{t} \sim \operatorname{IIDN}(0, \mathbb{I})$ is an $m \times 1$ vector that contains $m$ sources of uncertainty. The $k \times k$ matrix $\Phi$ is the autoregressive matrix for the set of state variables, $\theta$ is a $k \times 1$ vector with the unconditional means of the state variables and $\Psi$ is an $m \times k$ vector

\footnotetext{
${ }^{7}$ The discrete-time version of the Duffie and Kan (1996) model is derived in Backus, Foresi and Telmer (1998).
} 
that determines the sensitivity of the state variables to the uncertainty. Therefore, the constant matrix $\Psi^{\top} \Sigma \Psi$ describes the conditional covariance structure of the state variables.

The one-period stochastic discount factor $M_{t, t+1}$ is described by

$$
-\log M_{t+1}=\Gamma_{0}+\Gamma_{1}^{\top} \mathbf{s}_{t}+\frac{1}{2} \lambda\left(\mathbf{s}_{t}\right)^{\top} \Psi^{\top} \Sigma \Psi \lambda\left(\mathbf{s}_{t}\right)+\lambda\left(\mathbf{s}_{t}\right)^{\top} \Psi^{\top} \Sigma^{1 / 2} \varepsilon_{t+1} .
$$

where the $k \times 1$ vector $\Gamma_{1}$ represents the "factor loadings" for the pricing kernel and the $k \times 1$ vector $\lambda\left(\mathbf{s}_{t}\right)$ contains the potentially time-varying prices of risk. The prices of risk admit the affine representation

$$
\lambda\left(\mathbf{s}_{t}\right)=\mathbb{A}_{k, m}\left(\lambda_{0}+\lambda_{1} \mathbf{s}_{t}\right),
$$

where $\lambda_{0}$ is an $m \times 1$ vector, $\lambda_{1}$ is an $m \times k$ matrix and $\mathbb{A}_{k, m}$ is a $k \times m$ matrix that becomes $\mathbb{I}$ when $k=m$. The quadratic term $\frac{1}{2} \lambda\left(\mathbf{s}_{t}\right)^{\top} \Sigma \lambda\left(\mathbf{s}_{t}\right)$ is a correction that preserves the linearity of interest rates in the log-normal framework. This characterization conforms to the essentially affine framework in Duffee (2002), Dai and Singleton (2002) or Ang and Piazzesi (2003).

From this specification for the stochastic discount factor and the bond pricing equation (9) we can write interest rates as

$$
i_{t}^{(n)}=\frac{1}{n}\left[\mathcal{A}_{n}+\mathcal{B}_{n}^{\top} \mathbf{s}_{t}\right]
$$

where the parameters defining bond yields, $\mathcal{A}_{n}$ and the $k \times 1$ vector $\mathcal{B}_{n}$, are found recursively to be

$$
\begin{aligned}
& \mathcal{A}_{n}=\Gamma_{0}+\mathcal{A}_{n-1}+\mathcal{B}_{n-1}^{\top}\left[(\mathbb{I}-\Phi) \theta-\Sigma_{\Psi} \mathbb{A}_{k, m} \lambda_{0}\right]-\frac{1}{2} \mathcal{B}_{n-1}^{\top} \Sigma_{\Psi} \mathcal{B}_{n-1} \\
& \mathcal{B}_{n}^{\top}=\Gamma_{1}^{\top}+\mathcal{B}_{n-1}^{\top}\left[\Phi-\Sigma_{\Psi} \mathbb{A}_{k, m} \lambda_{1}\right]
\end{aligned}
$$

where $\Sigma_{\Psi}=\Psi^{\top} \Sigma \Psi$ with initial conditions $\mathcal{A}_{0}=0$ and $\mathcal{B}_{0}=\mathbf{0}$. The recursive equation for the factor loading parameters $\mathcal{B}_{n}$ allows us to observe the evolution across maturity of these loadings. In particular, if the market prices of risk are constant $\left(\lambda_{1}=0\right)$, the adjustment in the factor loadings is given by the autocorrelation matrix of the state variables. When the market prices of risk are time-varying the adjustment depends on the modified autocorrelation matrix $\Phi-\Sigma_{\Psi} \mathbb{A}_{k, m} \lambda_{1}$ which can be seen as the autocorrelation matrix for the state variables under the risk-neutral measure.

The equilibrium term structure for the economy can be represented as an affine term structure model of the class described above by imposing significant restrictions on the parameters. Proposition 1 presents a complete characterization for the term structure model that is consistent with equilibrium. It shows that three state variables are required to describe the dynamics of 
the term structure. The representation in the proposition is given for simplicity in terms of three macroeconomic variables: natural consumption growth and current and lagged inflation.

Proposition 1. The equilibrium characteristics of the economy and its associated nominal pricing kernel are represented by equations (11), (12) and (13) when

$$
\mathbf{s}_{t} \equiv\left(\Delta c_{t}^{n a t}, \pi_{t}, \pi_{t-1}\right)^{\top}
$$

and

$$
\begin{aligned}
& \Phi=\left[\begin{array}{ccc}
\phi_{c} & 0 & 0 \\
0 & \phi_{\epsilon} & 0 \\
0 & 1 & 0
\end{array}\right], \quad \theta=\left(\begin{array}{c}
\theta_{c} \\
\delta_{\epsilon} \\
-\delta_{\epsilon}
\end{array}\right), \quad \Psi^{\top}=\left[\begin{array}{cc}
1 & 0 \\
0 & \delta_{\epsilon} \\
0 & 0
\end{array}\right] \\
& \Sigma^{1 / 2}=\operatorname{diag}\left\{\sigma_{c}, \sigma_{\epsilon}\right\}, \quad \varepsilon=\left(\varepsilon_{c}, \varepsilon_{\epsilon}\right)^{\top}, \\
& \Gamma_{0}=-\log \beta+\theta_{\pi}+\gamma\left(1-\phi_{c}\right) \theta_{c}+(1-\gamma \rho)\left(1-\phi_{\epsilon}\right) \delta_{\pi}-\frac{1}{2} \gamma^{2} \sigma_{c}^{2}-\frac{1}{2}(1-\gamma \rho)^{2} \delta_{\epsilon}^{2} \sigma_{\epsilon}^{2} \text {, } \\
& \Gamma_{1}=\left[\begin{array}{lll}
\Gamma_{1,1} & \Gamma_{1,2} & \Gamma_{1,3}
\end{array}\right]^{\top} \\
& =\left[\begin{array}{lll}
\gamma\left(\phi_{c}-\eta \sigma_{c}^{2}\right)+\eta \mu & \phi_{\epsilon}+\left(1-\phi_{\epsilon}+\eta \sigma_{c}^{2}\right) \gamma \rho-\eta \rho \mu & -\eta \rho\left(\gamma \sigma_{c}^{2}-\mu\right)
\end{array}\right]^{\top}, \\
& \lambda_{0}=\left(\begin{array}{c}
\gamma \\
1-\gamma \rho
\end{array}\right), \quad \lambda_{1}=\eta\left[\begin{array}{ccc}
1 & -\rho & \rho \\
-\rho & \rho^{2} & -\rho^{2}
\end{array}\right], \quad \mathbb{A}_{3,2}=\left[\begin{array}{c}
\mathbb{I}_{2 \times 2} \\
\mathbf{0}_{1 \times 2}
\end{array}\right] \text {. }
\end{aligned}
$$

and

$$
\mu=\rho(1-\gamma \rho) \delta_{\epsilon}^{2} \sigma_{\epsilon}^{2}
$$

The policy-dependent parameter $\rho$ plays a significant role in the determination of the term structure given its impact on consumption growth and inflation. The relative weight of inflation in the policy objective function affects not only the sensitivity $\Gamma_{1}$ of $M_{t, t+1}$ to macroeconomic variables, but also it affects the market prices of natural consumption growth risk and cost-push shocks. We can notice that the constant component of the market price of supply shocks in $\lambda_{0}$ can be positive or negative depending on whether the effect of inflation on the (nominal) marginal utility of consumption is greater than the effect of the output gap. In particular, the constant component of the market price of supply shocks is positive if $\gamma^{-1}>\rho$, that is, if the relative weight of inflation in the policy objective function is low enough, a unit of supply shocks has greater effects on inflation than on consumption growth, in marginal utility terms.

Proposition 1 also shows us that the time-varying components of the market price of risk in $\lambda_{1}$ depend on the external habit parameter $\eta$ and the monetary policy parameter $\rho$. The particular case $\eta=0$, or constant relative risk aversion, implies a constant price of risk. For $\eta \neq 0$, the 
price of the two sources of uncertainty depend on the state of the economy. The time-varying component of the price of risk is

$$
\lambda_{1} \mathbf{s}_{t}=\eta\left[\begin{array}{c}
1 \\
-\rho
\end{array}\right] \Delta c_{t}^{n a t}+\eta \rho\left[\begin{array}{c}
-1 \\
\rho
\end{array}\right] \Delta \pi_{t} .
$$

Then, the negative dependence of consumption growth on inflation, generated by the optimal monetary policy, makes the price of risk to depend on inflation changes. A shock that moves the price of natural consumption growth in one direction moves the price of supply shocks in the opposite direction.

Sensitivity of the Market Prices of Risk to the Relative Weight of Inflation in the Policy Objective

Changes in the relative weight of inflation in the objective function of monetary policy, $\rho$, affect the price of natural consumption growth risk and supply shocks. An increase in the weight $\rho$ increases the sensitivity of inflation and the output gap to supply shocks and affects both prices of risk. Consider first the effect on the price of natural consumption growth. The effect is entirely driven by the existence of preference shocks $(\eta \neq 0)$ that are affected by lagged consumption growth. A positive (lagged) supply shock generates a greater reduction in lagged output gap (less lagged inflation), and thus a greater negative effect on aggregate consumption growth. If $\eta>0$, the marginal utility of consumption increases and the price of natural consumption risk declines. Effectively, it can be seen as a reduction in risk aversion for each unit of positive supply shocks that affect consumption growth. The effect is the opposite if $\eta$ is negative.

With respect to the price of supply shocks, it is affected even in the absence of preference shocks. The constant component $(1-\gamma \rho) \delta_{\epsilon}$ of this price of risk decreases when the relative weight of inflation in the policy objective function increases. The reason is less inflation for each unit of supply shocks, which reduces the nominal part of the pricing kernel, and more effects on the output gap, which reduces the related real component of the pricing kernel due to its negative effects on consumption growth. In addition, the existence of preference shocks makes the price of supply shocks to depend on lagged changes in supply shocks (lagged changes in inflation). The net effect of a higher $\rho$ depends on the combination of two effects. A higher relative weight on inflation increases the sensitivity of this price of risk to lagged consumption growth and, simultaneously, has negative effects on the output gap. It translates into higher sensitivities of the price of risk to lagged natural consumption growth and lagged changes in supply shocks. If $\eta>0$, it implies a lower price of risk for positive lagged natural consumption growth and a higher price of risk for positive lagged changes in supply shocks. 


\section{Analysis}

Our main interest is to understand how the term structure of interest rates is useful for the analysis of optimal monetary policy. We consider three possible applications of the yield curve for policy making and analyze them using the equilibrium framework presented above. First, the term structure of interest rates can be used to extract expectations about future short-term interest rates. This expectations can be seen as expectations about future monetary policy if the monetary authority implements the policy using an interest-rate rule. Second, the term structure is useful to extract macroeconomic information. Interest rates contain information about the current value and the expected evolution of macroeconomic variables such as consumption growth and inflation. Third, monetary policy might be implemented with interest rate rules that are based on term structure information such as interest rate levels or term spreads. The three type of analysis are described below and are complemented with a calibration exercise and a policy experiment in section sec:calibI. The purpose of the policy experiment is to understand how changes in monetary policy affect the three applications of the term structure to policy analysis. The change in monetary policy that is considered is a change in the relative weight that the monetary policy assigns to inflation in the policy objective function. This change can be linked to economic welfare as shown in the exercise.

\section{A Useful Change of State Variables}

It is convenient at this point to describe a tool that is used in the analysis below. We want to describe interest rates not only in terms of macroeconomic variables as in Proposition 1 but also in terms of financial variables such as term spreads. At the same time it is helpful to describe macroeconomic variables in terms of interest-rate information. These two tasks can be accomplished with appropriate changes of the set of state variables. Consider a new set of $l \leq k$ state variables represented by the $l \times 1$ vector $\hat{\mathbf{s}}_{t}$. These variables can be written as linear combinations of the original state variables in the form

$$
\hat{\mathbf{s}}_{t}=\mathcal{C}+\mathcal{D} \mathbf{s}_{t}
$$

where $\mathcal{C}$ is an $l \times 1$ vector and $\mathcal{D}$ an $l \times k$ matrix. If $l=k$ and $\mathcal{D}$ is invertible we can obtain again the original set of state variables as

$$
\mathbf{s}_{t}=\mathcal{D}^{-1}\left(\hat{\mathbf{s}}_{t}-\mathcal{C}\right) .
$$




\subsection{Time-Varying Term Premia and the Expectations Hypothesis of Interest Rates}

Long-term interest rates can be seen as risk-adjusted expectations of future short-term interest rates. Under the theory of the expectations hypothesis of interest rates, the risk adjustment of the expectations is constant or zero (pure expectations hypothesis). This theory is convenient to interpret the information of the term structure: changes in long-term rates simply reflect changes in expected future short-term rates. Unfortunately, empirical studies such as Campbell and Shiller (1991) or Fama and Bliss (1987) provide evidence of deviations from the expectations hypothesis in the data. This rejection, that can be interpreted as evidence of time-varying term premia, makes it difficult the interpretation of the information of the yield curve.

Time variation in term premia presents a non-trivial challenge for policy makers that want to use the term structure for forecasting purposes. If the term premia are significantly large and volatile, using the expectations hypothesis of interest rates to forecast short-term rates can be misleading. As an alternative, term premia can be extracted from an equilibrium model. However, the latter approach is exposed to the validity of the model. This subsection presents the implications of the equilibrium term structure model studied above for time variation in term premia.

Consider the one-period term premium on an $n$-period bond defined by

$$
\xi_{t}^{(n)} \equiv i_{t}^{(n)}-\frac{1}{n}\left[i_{t}+(n-1) \mathbb{E}_{t} i_{t+1}^{(n-1)}\right]
$$

The no-arbitrage recursive equations (14) imply that

$$
\xi_{t}^{(n)}=\frac{1}{n}\left[\xi_{\mathcal{A}, n}+\xi_{\mathcal{B}, n}^{\top} \mathbf{s}_{t}\right]
$$

with coefficients given by

$$
\xi_{\mathcal{A}, n}=-\mathcal{B}_{n-1}^{\top} \Sigma_{\Psi}\left(\mathbb{A}_{k, m} \lambda_{0}+\frac{1}{2} \mathcal{B}_{n-1}\right) \quad \text { and } \quad \xi_{\mathcal{B}, n}^{\top}=-\mathcal{B}_{n-1}^{\top} \Sigma_{\Psi} \mathbb{A}_{k, m} \lambda_{1}
$$

It can be inferred from these equations that a necessary condition for time-variation in term premia is a time-varying market price of risk $\left(\lambda_{1} \neq 0\right)$. As a result, the habit in the economic model and the relative weight assigned to inflation in the policy objective are fundamental to characterize deviations from the expectations hypothesis. To see this, consider the Campbell and Shiller (1991) coefficients, $\beta^{(n)}$, associated to the regression

$$
i_{t+1}^{(n-1)}-i_{t}^{(n)}=\alpha^{(n)}+\frac{\beta_{C S}^{(n)}}{n-1}\left(i_{t}^{(n)}-i_{t}\right)+\varepsilon_{C S, t}^{(n)}
$$


Under the expectations hypothesis the $\beta_{C S}^{(n)}$ coefficients are equal to 1 . Using equation (16) these coefficients can be written as

$$
\beta_{C S}^{(n)}=1-n \frac{\operatorname{cov}\left(i_{t}^{(n)}-i_{t}, \xi_{t}^{(n)}\right)}{\operatorname{var}\left(i_{t}^{(n)}-i_{t}\right)},
$$

implying that deviations from the expectations hypothesis are potentially captured by the correlation between term spreads and one-period term premia.

To simplify the analysis, consider the relation between expected excess returns and term premia $\xi_{t}^{(n)}$. Let $x r_{t, t+1}^{(n)}$ be the one-period excess return for holding an $n$-period bond with respect to a one-period risk-free bond. The expected excess return is

$$
\mathbb{E}_{t}\left[x r_{t, t+1}^{(n)}\right]=-(n+1) \mathbb{E}_{t} i_{t+1}^{(n-1)}+n i_{t}^{(n)}-i_{t}=n \xi_{t}^{(n)}
$$

From this representation for expected excess returns and using equation (16) recursively, the one-period interest rate is

$$
i_{t}^{(n)}=\frac{1}{n} \mathbb{E}_{t}\left[\sum_{j=0}^{n-1} i_{t+j}\right]+\frac{1}{n} \mathbb{E}_{t}\left[\sum_{j=0}^{n-2} x r_{t+j, t+j+1}^{(n-j)}\right] .
$$

The first component of the short-term rate reflects the pure expectations hypothesis. The second component contains the sum of the one-period expected excess returns embedded in the $n$-period bond until maturity. Deviations from the expectations hypothesis can be captured if this component is not constant.

\subsection{Expectations About Future Monetary Policy}

If the expectations hypothesis holds in an economy where the monetary authority implements monetary policy using the short-term rate, one-period forward rates for different horizons are good indicators of expected future monetary policy. However, time variation in term premia complicates the analysis. The forward rate in this environment can be a misleading indicator of future monetary policy. In this subsection we provide a characterization of the differences between forward rates and expected future short rates and show that this difference may depend on the type of policy that is conducted.

Denote the one-period forward rate at time $t$ between $t+n$ and $t+n+1$ by $f_{t, n}^{(1)} \equiv f_{t, n}$. By no-arbitrage this rate has to be equal to

$$
f_{t, n}=(n+1) i_{t}^{(n+1)}-n i_{t}^{(n)} .
$$


Differencing (19) we obtain that the difference between the expected value of the one-period interest rate $n$ periods in the future and the forward rate is

$$
\begin{aligned}
\mathbb{E}_{t}\left[i_{t+n}\right]-f_{t, n} & =-\mathbb{E}_{t}\left[x r_{t, t+1}^{(n+1)}\right]-\mathbb{E}_{t}\left[\sum_{j=2}^{n-2} x r_{t+j+1, t+j+2}^{(n-j)}-x r_{t+j, t+j+1}^{(n-j)}\right] \\
& =-\mathbb{E}_{t}\left[x r_{t, t+1}^{(n+1)}\right]+\sum_{j=2}^{n-2} \xi_{\mathcal{B}, n-j}^{\top}(\mathbb{I}-\Phi)\left(\theta-\mathbb{E}_{t}\left[\mathbf{s}_{t+j}\right]\right)
\end{aligned}
$$

Thus, the expected future short-rate differs from the forward rate in the presence of term premia. The first component of the difference is the expected one-period excess return from $n$ to $n+1$. This term survives even if term premia are constant. The second term results from time variation in term premia. It captures expected changes in one-period excess returns during the life of the bond with maturity at $t+n$. It can be seen that this term contributes to the difference between the expected short rate and the forward rate as long as the conditional expectation of the state variables during the life of the bond differ from the unconditional mean. Therefore, its effects are not observed on the long-run difference but can be analyzed using impulse responses to shocks that make the current economic conditions deviate from their long-run mean. This decomposition allows us to describe the usefulness of the forward rate as an indicator of expected monetary policy for policies with different distaste for inflation and different economic conditions.

One way to obtain expected future monetary policy given the limitations of looking directly at the appropriate forward rate is to use additional information from the term structure. As an example consider the change of state variables represented in equation (15) where the new set of state variables is

$$
\hat{\mathbf{s}}_{t} \equiv\left(i_{t}, f_{t, n}, \pi_{t-1}\right)
$$

That is, besides the forward rate, we can use the short term rate and lagged inflation to obtain the expected short rate for any horizon. If the expectations hypothesis holds we should obtain a loading coefficient of 1 for the forward rate and zero coefficients for the other two variables in the representation

$$
\mathbb{E}_{t}\left[i_{t+n}\right]=\mathcal{A}_{1}+\Gamma_{1}^{\top}\left(\mathbb{I}-\Phi^{n}\right) \theta-\Gamma_{1}^{\top} \Phi^{n} \mathcal{D}^{-1} \mathcal{C}+\Gamma_{1}^{\top} \Phi^{n} \mathcal{D}^{-1} \hat{\mathbf{s}}_{t}
$$

where

$$
\mathcal{C}=\left(\begin{array}{c}
\mathcal{A}_{1} \\
\mathcal{A}_{n-1}-\mathcal{A}_{n} \\
0
\end{array}\right) \quad \text { and } \quad \mathcal{D}=\left(\begin{array}{c}
\mathcal{B}_{1}^{\top} \\
\mathcal{B}_{n-1}^{\top}-\mathcal{B}_{n}^{\top} \\
e_{3}^{\top}
\end{array}\right)
$$

The calibration and policy experiment below provide a comparison of expected short-term rates 
for different maturities and different weights for inflation in the policy objective function.

\subsection{The Macroeconomic Content of the Term Structure}

An important indicator of the effectiveness of monetary policy and, thus, a guideline for policy making is the expected future inflation. This indicator provides an idea of the credibility of monetary policy about stabilizing prices in the future and might help take appropriate measures when it signals a decline in credibility. The term structure can be used to extract information about expectations of future inflation for different horizons as well as for other macroeconomic indicators. This task is, however, far from simple even under the expectations hypothesis.

Consider, for instance, the expected inflation one-period in the future implied by the term structure. Let $r_{t}$ be the one-period continuously-compounded real rate. From the no-arbitrage price of a one-period real bond we can obtain the interest rate as

$$
e^{-r_{t}}=\mathbb{E}_{t}\left[M_{t, t+1}^{r e a l}\right]=\mathbb{E}_{t}\left[\exp \left(\log \beta-\gamma \Delta c_{t+1}+\Delta q_{t+1}\right)\right]
$$

Using this equation and equation (10) for the nominal one-period rate, we can express the difference between the nominal rate and the real rate plus expected inflation as

$$
\begin{aligned}
i_{t}-\left(r_{t}+\theta_{\pi}+\mathbb{E}_{t} \pi_{t+1}\right) & =-\left(\gamma+\eta \Delta c_{t}\right) \operatorname{cov}_{t}\left(\Delta c_{t+1}, \pi_{t+1}\right)-\frac{1}{2} \operatorname{var}_{t}\left(\pi_{t+1}\right) \\
& =\left[\left(\gamma+\eta \Delta c_{t}\right) \rho-\frac{1}{2}\right] \operatorname{var}_{t}\left(\pi_{t+1}\right)=\left[e_{1}^{\top} \lambda\left(\mathbf{s}_{t}\right)-\frac{1}{2}\right] e_{2}^{\top} \Sigma_{\Psi} e_{2}
\end{aligned}
$$

where $e_{j}$ denotes the $k \times 1$ vector with a one in the $j$-th position and zeros everywhere else. This equation is helpful to understand that the difference between the nominal interest rate and the real rate is not only expected inflation when inflation and consumption growth are correlated. This correlation is determined by the optimal policy followed by the monetary authority. In addition, the variability of inflation adds a precautionary savings effect to the difference. The last equality shows that the difference depends on the market price of risk. When it is time-varying, the expectations hypothesis does not hold and the difference is not constant. Then, the existence

of time-varying risk premia makes it difficult to extract expected inflation from the yield curve. In this subsection we show how the term structure can be used to overcome these difficulties.

Let $m v_{t}$ be the set of macroeconomic variables to be analyzed. Here we restrict the analysis to $m v_{t}=\left\{\Delta c_{t}, \pi_{t}\right\}$. The current values for these variables and current expectations about future values can be described in terms of yield curve information such as rate levels or term spreads. Our main interest is to understand the explanatory power of term structure information about 
these variables. This task can be accomplished running regressions of the form

$$
m v_{t+h}=\alpha_{m v, h}+\boldsymbol{\beta}_{m v, h}^{\top} \hat{\mathbf{s}}_{t}+\varepsilon_{m v, h},
$$

for different horizons $h \geq 0$, where $\boldsymbol{\beta}$ is an $l \times 1$ vector (for $l \leq k$ ) that contains the loadings on the $l$ explanatory variables in the set of state variables $\hat{\mathbf{s}}_{t}$. The explanatory variables can be described in terms of the original state variables $\mathbf{s}_{t}$ using the change of variables characterized in equation (15). In addition, the macroeconomic variables can be written in terms of the original variables as $m v_{t+h}=e_{m v}^{\top} \mathbf{s}_{t+h}$ for the appropriate $k \times 1$ vector $e_{m v}$. Therefore, the regression loadings are given by

$$
\boldsymbol{\beta}_{m v, h}=\left(\mathcal{D} \operatorname{var}\left(\mathbf{s}_{t}\right) \mathcal{D}^{\top}\right)^{-1} \mathcal{D} \operatorname{var}\left(\mathbf{s}_{t}\right)\left(\Phi^{h}\right)^{\top} e_{m v}
$$

where the unconditional variance of the state variables, $\operatorname{var}\left(\mathbf{s}_{t}\right)$, satisfies the Lyapunov equation $\operatorname{var}\left(\mathbf{s}_{t}\right)=\Phi \operatorname{var}\left(\mathbf{s}_{t}\right) \Phi^{\top}+\Sigma_{\Psi}$. This derivation is obtained using the fact, from equation (11), that the process for the state variables at time $t+h$ is

$$
\mathbf{s}_{t+h}=\left(\mathbb{I}-\Phi^{h}\right) \theta+\Phi^{h} \mathbf{s}_{t}+\sum_{j=1}^{h} \Phi^{h-j} \Psi^{\top} \Sigma^{1 / 2} \varepsilon_{t+j} .
$$

It is also useful to understand the fraction of the variability of current and future macroeconomic conditions that is explained by the regression explanatory variables. It can be obtained by computing the model-implied $R^{2}$ 's associated with each regression, given by

$$
R_{m v, h}^{2}=\frac{\boldsymbol{\beta}_{m v, h}^{\top} \mathcal{D} \operatorname{var}\left(\mathbf{s}_{t}\right) \mathcal{D}^{\top} \boldsymbol{\beta}_{m v, h}}{e_{m v}^{\top}\left[\Phi^{h} \operatorname{var}\left(\mathbf{s}_{t}\right)\left(\Phi^{h}\right)^{\top}+\sum_{j=1}^{h} \Phi^{h-j} \Sigma_{\Psi}\left(\Phi^{h-j}\right)^{\top}\right] e_{m v}} .
$$

The calibration and policy experiment below present different regressions that are useful to understand the macroeconomic content of the term structure depending on the relative weight of inflation in the policy objective function. In particular, regressions with one, two and three regressors are presented. Univariate regressions where the regressor is the term spread or its expectations hypothesis component are analyzed. It provides insights about the importance of deviations from the expectations hypothesis (time-varying term premia) explaining the current and future macroeconomic conditions. In the bivariate regressions, the regressors are the oneperiod interest rate and the term spread for some maturity. These regressions are useful to ask whether the predictability of different macro variables is explained by the short-term rate or the spread. The analysis is complemented with regressions where $l=k=3$. The idea of this regressions is to add to the list of regressors one lagged macro variable and observe the maximum explanatory power that the system allows. Moreover, this type of regressions is useful to obtain an 
accurate value for a macroeconomic variable $m v_{t}$ from the term structure. This can be a useful tool when the current macroeconomic value is unobservable at time $t$ or reported with noise. This is possible under the reasonable assumption that the current term structure and one-period lagged macro variables are known.

\subsection{Term-Structure-Based Policy Rules}

The optimal monetary policy described in section 2 can be implemented using an interest-rate policy rule. The level of the one-period nominal interest rate is then determined by a reaction function that responds to a set of variables known at the moment of implementation. A popular example of this implementation procedure is the Taylor (1993) rule, where the interest rate is a deterministic function of the output gap (de-trended GDP) and inflation (deviations from a trend). However, the operational feasibility of such a rule can be questioned given the informational requirements that it implies. For instance, the output gap is an unobservable variable and its measurement implies noise. Moreover, information about output growth and inflation takes time to collect and is subject to sampling error and revisions. In summary, the monetary authority is limited by the availability and quality of economic data.

Subsection 3.3 shows that current economic conditions can be extracted from long-term interest rates using an equilibrium (no-arbitrage) model of the term structure. Since developed bond markets provide accurate interest rates for different maturities on real-time, it suggests that non-operational macroeconomic-based policy rules can be re-expressed as operational rules where the short-term interest rate is set responding to term-structure information. An analysis of this type of rules is presented here.

The equilibrium one-period interest rate in equation (10) can be written as

$$
i_{t}=\Gamma_{0}+\Gamma_{1,1} \Delta c_{t}^{n a t}+\Gamma_{1,2} \pi_{t}+\Gamma_{1,3} \pi_{t-1}
$$

from Proposition 1. Assuming that this equilibrium representation satisfies some conditions, ${ }^{8}$ this representation provides a rule to set the interest rate. This rule can be expressed in terms of term-structure information using an appropriate change of variables. In particular, we have interest in rules that react to current and lagged term structure information such as interest rate levels and term spreads. These rules would allow us to see which sectors of the yield curve are important for policy purposes and how the rule should be modified to implement changes in the relative weight of inflation in the policy objective function (2).

\footnotetext{
${ }^{8}$ These conditions, known as the Taylor principle, deal with the indeterminacy of equilibrium that might arise from using an interest-rate rule. See Woodford (2003) and Cochrane (2006) for determinacy and uniqueness of equilibrium in this setting.
} 
The first group of rules to analyze are those where the short-term rate reacts to the current term spread for a specific maturity, the current level of a macroeconomic variable $m v_{t}=\left\{\Delta c_{t}, \pi_{t}\right\}$ and the one-period lagged inflation. These rules can be obtained from a change of state variables as in equation (15) where $\hat{\mathbf{s}}_{t}=\left(i_{t}^{(n)}-i_{t}, m v_{t}, \pi_{t-1}\right)^{\top}$ and

$$
\mathcal{C}=\left(\begin{array}{c}
\frac{1}{n} \mathcal{A}_{n}-\mathcal{A}_{1} \\
0 \\
0
\end{array}\right) \quad \text { and } \quad \mathcal{D}=\left[\begin{array}{c}
\frac{1}{n} \mathcal{B}_{n}^{\top}-\mathcal{B}_{1}^{\top} \\
e_{m v}^{\top} \\
e_{3}^{\top}
\end{array}\right]
$$

The rule for the one-period interest rate becomes

$$
i_{t}=\mathcal{A}_{1}-\mathcal{B}_{1}^{\top} \mathcal{D}^{-1} \mathcal{C}+\mathcal{B}_{1}^{\top} \mathcal{D}^{-1} \hat{\mathbf{s}}_{t}
$$

The calibration and policy experiment in subsection 3.5 provide numerical examples of these rules for different maturities and different weights for inflation in the objective function (2). In particular, this exercise allows to see what sectors of the yield curve should be used in order to minimize the weight of the contemporaneous macro variable in the rule.

The second group of rules are those rules that include a lagged value for the short-term interest rate. These rules capture the idea of interest-rate smoothing by the monetary authority. The appendix shows an extension of the procedure in Gallmeyer, Hollifield and Zin (2005) to characterize these rules. ${ }^{9}$ Consider the affine vector-representation

$$
\left(\begin{array}{c}
i_{t} \\
i_{t}^{(n)}-i_{t}
\end{array}\right)=\mathcal{F}+\mathcal{G}\left(\begin{array}{c}
i_{t-1} \\
i_{t-1}^{(n)}-i_{t-1}
\end{array}\right)+\mathcal{H} \varepsilon_{t}+\mathcal{I} \varepsilon_{t-1},
$$

where $\mathcal{G}, \mathcal{H}$ and $\mathcal{I}$ are $2 \times 2$ matrices. Manipulating this system as shown in the appendix, provides a representation for the short-term interest rate given by

$$
\begin{aligned}
i_{t} & =\mathcal{F}_{1}-\mathcal{G}_{12 / 22} \mathcal{F}_{2}+\left(\mathcal{G}_{11}-\mathcal{G}_{12 / 22} \mathcal{G}_{21}\right) i_{t-1}+\frac{\mathcal{G}_{12}}{\mathcal{G}_{22}}\left(i_{t}^{(n)}-i_{t}\right) \\
& +\left[\mathcal{H}_{1}-\mathcal{G}_{12 / 22} \mathcal{H}_{2}\right] \varepsilon_{t}+\left[\mathcal{I}_{1}-\mathcal{G}_{12 / 22} \mathcal{I}_{2}\right] \varepsilon_{t-1}
\end{aligned}
$$

where $\mathcal{G}_{12 / 22}=\frac{\mathcal{G}_{12}}{\mathcal{G}_{22}}$ and the matrix and vector sub-indices denote partitions that are described in the appendix.

This particular type of representation suggests a policy rule where the interest rate is set responding systematically to the lagged value of the interest rate and the current value of an

\footnotetext{
${ }^{9}$ The extension consists in finding the appropriate representation for the interest rate when there are current and lagged values of the same variable in the set of state variables $\mathbf{s}_{t}$, that is, when the matrix $\Phi$ in equation (11) is not full rank.
} 
interest rate spread. The additional uncertainty terms can be seen as monetary policy shocks. These rules are analyzed in subsection 3.5 using spreads of different maturities to understand the dependence of an interest-rate smoothing rule on the term structure.

\subsection{Calibration and Policy Experiment}

This section contains a numerical exercise where the model is calibrated to data and the analysis described in section 3 is performed. In addition, a policy experiment that consists in reducing the weight of inflation in the policy objective function is conducted. This experiment is justified by the possibility of implementing welfare-improving policies by changing the weight that the monetary authority assigns to inflation in the objective function. Therefore, comparisons in several dimensions between policies with high and low distastes for inflation are provided.

\subsubsection{Data and Parameter Values}

We use quarterly U.S. data from 1976:1 to 2005:4 for interest rates, consumption and consumer prices. The zero-coupon yields for 1 to 10 year bonds are obtained using the Svensson (1994) methodology applied to off-the-run Treasury coupon securities at the Federal Reserve Board. ${ }^{10}$ The short-term nominal interest rate is the 3-month T-bill rate from the Fama risk-free rates database. The consumption growth series was constructed using quarterly data on real per capita consumption of nondurables and services from the Bureau of Economic Analysis. The inflation series was constructed to capture inflation related only to non-durables and services consumption, following the methodology in Piazzesi and Schneider (2006).

The model parameters were chosen to match selected macroeconomic and term structure statistics. Appendix B provides analytical computations of the model-implied statistics and some details of the calibration. The procedure allows us to perfectly match the means, standard deviations and the autocorrelations of consumption growth and inflation. We obtain the weight of inflation in the policy objective function (2) by matching the correlation between consumption growth and inflation. This weight is obtained from

$$
\hat{\rho}=-\frac{1}{1-\hat{\phi}_{\epsilon}} \frac{\operatorname{cõv}\left(\Delta c_{t}, \pi_{t}\right)}{\operatorname{vãr}\left(\pi_{t}\right)}
$$

where the " $\wedge$ " symbol denotes the selected parameter value and " $\sim$ is the sample statistic. It is clear from the equation above that the model associates stronger negative correlations between consumption growth and inflation with a stronger distate for inflation.

Table 1 shows the parameter values used in the calibration. It is assumed for simplicity that

\footnotetext{
${ }^{10}$ The data series are available at http://www.federalreserve.gov/pubs/feds/2006/200628/feds200628.xls.
} 
Table 1: Parameter Values

\begin{tabular}{cc|cc|cc|cc}
\hline$\beta$ & 0.9999 & $\phi_{c}$ & 0.9874 & $\theta_{\pi}$ & $1.0228 \times 10^{-2}$ & $\rho$ & 0.8437 \\
$\gamma$ & 0.975 & $\sigma_{c}$ & $4.1503 \times 10^{-4}$ & $x^{*}$ & 0 & $\phi_{\epsilon}$ & 0.8298 \\
$\theta_{c}$ & $4.9312 \times 10^{-3}$ & $\eta$ & 22445 & $\kappa$ & 0.024 & $\sigma_{\epsilon}$ & $6.4259 \times 10^{-4}$ \\
\hline
\end{tabular}

$\hat{x}^{*}=0$. That is, the natural rate of consumption in the model economy is efficient and, as a consequence, there is no inflation bias $\left(\hat{\delta}_{\pi}=0\right)$. The coefficient $\kappa$ that captures the relation between inflation and the output gap in the aggregate supply equation was obtained from the monetary policy literature. The implied weight of inflation in the policy function is high, given

by $\frac{\hat{\rho}}{\hat{\rho}+\hat{\kappa}}=97.23 \%$, as well as the autocorrelation of the natural consumption growth, $\phi_{c}$. The latter is required to match the variability of consumption growth. Given that the autocorrelation of the supply shock, $\phi_{\epsilon}$, is set to match the autocorrelation of inflation during the sample period, the high level of $\phi_{c}$ plays a significant role trying to capture the volatility of long-term rates. The preference shock parameter $\eta$ is positive, implying that positive lagged consumption growth decreases the level of utility today. Since consumption growth is negatively related to changes in inflation, a positive $\eta$ also implies that the level of utility increases with positive lagged changes in inflation.

\subsubsection{A Welfare-Improving Policy and a Policy Experiment}

The policy analyzed in section 2 is the optimal policy under discretion. Kydland and Prescott (1977) show that, given the forward-looking nature of economic agents, a monetary authority can obtain better results in terms of economic welfare if it is able to conduct a policy under commitment. This is possible given the ability of commitment affecting agents' expectations. A welfare-improving policy has direct effects on the equilibrium macroeconomic dynamics and, therefore, it is reasonable to think that the dynamics of the term structure, its predictive power and economic content will be different under such a policy than under discretion. We analyze here the effects of conducting a "restricted optimal" policy under commitment. It is restricted because it is optimal within a family of policies where the level of inflation and the output gap depend linearly on supply shocks.

Woodford (2003) suggests decomposing the policy objective function (2) as

$$
\begin{aligned}
\mathbb{E}\left\{\sum_{t=0}^{\infty} \beta^{t}\left[\rho \pi_{t}^{2}+\kappa\left(x_{t}-x^{*}\right)^{2}\right]\right\} & =\sum_{t=0}^{\infty} \beta^{t}\left(\rho \mathbb{E}\left[\pi_{t}\right]^{2}+\kappa \mathbb{E}\left[x_{t}-x^{*}\right]^{2}\right) \\
& +\sum_{t=0}^{\infty} \beta^{t}\left[\rho \operatorname{var}\left(\pi_{t}\right)+\kappa \operatorname{var}\left(x_{t}\right)\right] .
\end{aligned}
$$


He refers to the second term as the stabilization component and proposes to rank policies (for welfare purposes) according to the size of this component. This criterion is used here to find the optimal policy within a restricted family of policies.

Consider the family of policies where the output gap and inflation depend linearly on the supply shock. The appendix shows the derivation of the policy under commitment within this family that minimizes the stabilization component above. This policy implies the targeting rule

$$
x_{t}-x^{*}=-\frac{\rho}{1-\beta \phi_{\epsilon}} \pi_{t}=-\rho_{r c} \pi_{t} .
$$

If supply shocks are autocorrelated, the "restricted optimal" policy involves a stronger reaction of the output gap to inflation than in the discretionary case in equation (5). Moreover, this policy can be implemented under discretion by increasing the relative weight of inflation in the policy objective function to $\rho_{r c}$. As a result, the analysis in section (2) remains valid for this type of policy rules.

The considerations above constitute the basis for the policy experiment conducted here, allowing us to provide welfare interpretations. We assume that during the sample period the Federal Reserve implemented the "restricted optimal" policy under commitment by raising the weight of inflation in the policy objective function. It implies that $\hat{\rho}=\rho_{r c}$, and therefore the "true" relative inflation weight was

$$
\rho_{\text {low }}=\hat{\rho}\left(1-\hat{\beta} \hat{\phi}_{\epsilon}\right)=0.1437
$$

and $\frac{\rho_{\text {low }}}{\rho_{\text {low }}+\kappa}=85.69 \%$. The policy experiment consists then on reducing the relative weight of inflation to $\rho_{\text {low }}$ to observe its macroeconomic and term structure implications. We refer to the calibrated model and the experiment model as the $\rho$-economy and $\rho_{l o w}$-economy, respectively.

\subsubsection{Consumption Growth, Inflation and the Yield Curve}

This section analyzes the macroeconomic and interest-rate differences between the two economies described above. Table 2 shows selected statistics for the data and the two model economies.

\section{Macroeconomic Variables}

The $\rho$-economy matches the macroeconomic statistics of the data by construction. It is observed that the policy that is less conservative about inflation does not affect the long-run averages for consumption growth and inflation. In the absence of an inflation bias, the monetary authority is able on average to reach the inflation target. Also, prices are flexible on the long-run and consumption growth follows the trend of natural consumption growth. The differences between the two economies are observed in terms of the variability of the macroeconomic variables. The optimal targeting equation (5) shows us that a less conservative policy about inflation allows less 
Table 2: Data and model-implied descriptive statistics.

\begin{tabular}{lccc}
\hline & Data & $\rho$ & $\rho_{\text {low }}$ \\
\hline $\mathbb{E}\left[\Delta c_{t}\right] \times 4$ & $1.97 \%$ & $1.97 \%$ & $1.97 \%$ \\
$\mathbb{E}\left[\pi_{t}\right] \times 4$ & $4.09 \%$ & $4.09 \%$ & $4.09 \%$ \\
$\sigma\left(\Delta c_{t}\right) \times 4$ & $1.59 \%$ & $1.59 \%$ & $1.07 \%$ \\
$\sigma\left(\pi_{t}\right) \times 4$ & $2.42 \%$ & $2.42 \%$ & $2.65 \%$ \\
$\operatorname{corr}\left(\Delta c_{t}, \Delta c_{t-1}\right)$ & 0.38 & 0.38 & 0.94 \\
$\operatorname{corr}\left(\pi_{t}, \pi_{t-1}\right)$ & 0.83 & 0.83 & 0.83 \\
$\operatorname{corr}\left(\Delta c_{t}, \pi_{t}\right)$ & -0.22 & -0.22 & -0.06 \\
\hline $\mathbb{E}\left[i_{t}\right] \times 4$ & $6.12 \%$ & $6.12 \%$ & $6.12 \%$ \\
$\mathbb{E}\left[i_{t}^{(20)}\right] \times 4$ & $7.38 \%$ & $7.59 \%$ & $6.30 \%$ \\
$\mathbb{E}\left[i_{t}^{(40)}\right] \times 4$ & $7.80 \%$ & $7.80 \%$ & $6.26 \%$ \\
$\sigma\left(i_{t}\right) \times 4$ & $3.21 \%$ & $2.56 \%$ & $2.49 \%$ \\
$\sigma\left(i_{t}^{(20)}\right) \times 4$ & $2.78 \%$ & $1.83 \%$ & $1.23 \%$ \\
$\sigma\left(i_{t}^{(40)}\right) \times 4$ & $2.52 \%$ & $1.64 \%$ & $0.98 \%$ \\
$\operatorname{corr}\left(i_{t}, i_{t-1}\right)$ & 0.93 & 0.86 & 0.86 \\
$\operatorname{corr}\left(i_{t}, i_{t}^{(20)}\right)$ & 0.87 & 0.75 & 0.84 \\
$\operatorname{corr}\left(i_{t}, i_{t}^{(40)}\right)$ & 0.84 & 0.61 & 0.70 \\
\hline $\operatorname{corr}\left(i_{t}, \Delta c_{t}\right)$ & -0.08 & 0.08 & 0.36 \\
$\operatorname{corr}\left(i_{t}, \pi_{t}\right)$ & 0.68 & 0.91 & 0.91 \\
\hline
\end{tabular}

deviations in the output gap from its target. It translates into a higher volatility of inflation and a lower volatility of consumption growth. Simultaneously, a policy under discretion is not able to break the direct link between the persistence of the supply shocks and the persistence of inflation. Therefore, the autocorrelation of inflation is the same in the two economies. However, the greater weight of the output gap in the policy objective function makes consumption growth to increase the correlation with the natural rate of consumption growth. Given the high autocorrelation of natural consumption growth in the calibration, it implies an increase in the autocorrelation of consumption growth in the $\rho_{l o w}$-economy. As mentioned before, a lower inflation weight reduces the negative correlation between consumption growth and inflation.

The lowest panel of Table 2 shows the correlation of the one-period rate with consumption growth and inflation. While the correlation with inflation is practically unaffected by $\rho$, the correlation with consumption growth increases, reflecting the reduction of the negative impact of inflation on consumption. The $\rho$-economy implies a slightly positive correlation of the short-term rate with consumption growth which differs from the slightly negative correlation observed in the data. With respect to the correlation with inflation, it is positive and higher than the one observed during the sample period. 
The Term Structure of Interest Rates

Some important properties of interest rates implied by the data and the model economies are presented in Table 2 and Figure 1. The model parameters $\beta, \gamma$ and $\eta$ for the $\rho$-economy were used to match the level of the 3 -month and 10 -year interest rates and minimize the difference between the short-term rate volatility implied by the model and that of the data. Although the slope of the yield curve is captured, Panel A of the figure shows that the level of interest rates for intermediate maturities are not closely matched. Panel B allows us to see the inability of the model to capture simultaneously the high volatility of interest rates and the volatility of consumption growth and inflation. Interest rates are not volatile enough when the model captures macroeconomic volatility.
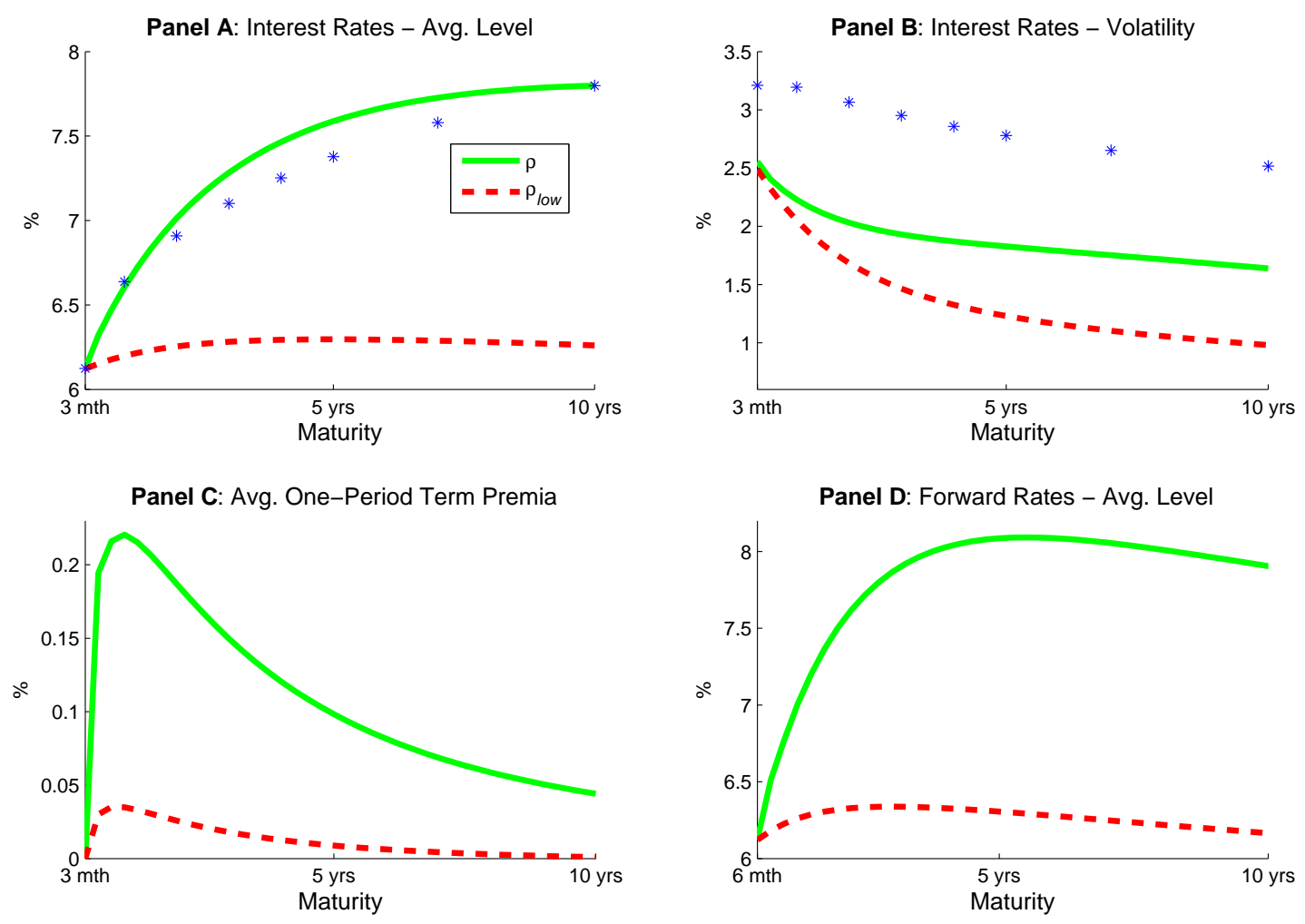

Figure 1: Nominal Interest Rate Properties. The $(*)$ denotes 1976-2005 data.

However, the model is successful generating significant volatility of long-term rates relative to the volatility of short-term rates. The ratios 10 -year rate volatility to 3 -month rate volatility implied by the data and the $\rho$-economy are $61 \%$ and $41 \%$, respectively. This achievement is due to the high persistence of the natural consumption growth process. However, the ratio decreases to $15 \%$ in the $\rho_{\text {low }}$-economy. This is the result of a reduced time variation in the market prices of risk when the monetary authority is less concerned about inflation.

Panel $\mathrm{C}$ of Figure 1 also shows an important decrease in the size of one-period term premia 
(and their volatility).It explains the significant decline in the slope of the yield curve. Thus, the model implies that if the monetary authority assigns more weight to the output gap in the objective function, we should observe lower term premia. Equivalently, a high relative weight on inflation creates significant distortions in the real side of the economy, and bondholders demand high compensations for holding long-term bonds despite the benefits of a reduced inflation risk. However, the reduction in the inflation risk is significant enough to offset the higher systematic risk of holding long-term bonds and it allows for an increase in economic welfare.

\subsubsection{Expected Future Monetary Policy}

The analysis in section 3.2 evidences the difficulties in extracting expectations about future shortterm rates from forward rates when the yield curve exhibits time-varying expected returns. It also shows how these difficulties might be overcome using, in addition to the forward rate, macroeconomic and other term structure information to extract expectations about future monetary policy. This section intends to quantify the differences between the forward rate and the expected short-rate in the $\rho$-economy and the $\rho_{\text {low }}$-economy, on average and when some shocks impact the economy. In addition, it presents the sensitivity of expected future one-period rates for different horizons to the current short-term rate, the appropriate forward rate and lagged inflation.
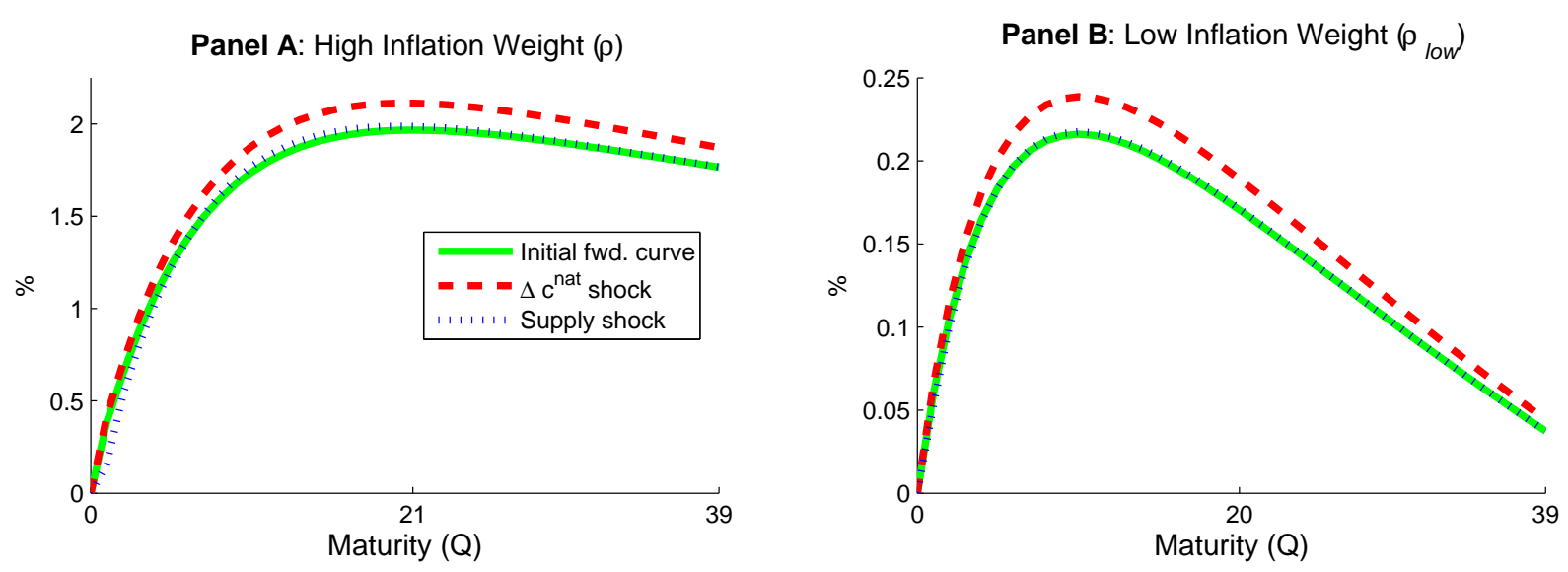

Figure 2: Difference between forward rates and expected one-period rate for different horizons. The "Initial fwd. curve" line denotes the unconditional difference $\mathbb{E}\left[f_{t, n}-i_{t+n}\right]$. The other two lines show the differences conditional on a natural consumption growth shock and a supply shock, respectively, of size one.

It can be observed from equation (20) that the difference between the forward rate and the expected future short-term rate has two components. The first component is the a one-period expected excess return and the second component captures changes in expected excess returns 
during the life of the bond linked to the forward rate. Unconditionally, the second component vanishes and the long-run differences between forward rates and expected short rates are reflected only in the first component. Figure 2 presents these differences for the two model economies. When the weight of inflation is high in the policy objective function, the differences between the forward rate and the average short-rate tend to increase with maturity (this is consequence of the upward sloping yield curve). When the weight of inflation decreases, the yield curve tends to be flatter, the differences for intermediate maturities are high (but much lower than in the $\rho$-economy and decline for longer maturities.

Figure 2 also shows variations in the difference between forward rates and expected short rates as a result of shocks to natural consumption growth and supply shocks. While supply shocks do not considerably affect this difference, shocks to natural consumption growth do. The impact is quantitatively more significant in the $\rho$-economy than in the $\rho_{\text {low }}$-economy. A positive shock to natural consumption increases the forward rate more than the associated expected shortrate, implying also changes in expected excess returns for different maturities. It indicates that a shock to natural consumption growth does not require the one-to-one reaction in future monetary policy (interest rate) that seems to require a supply shock. In summary, the different responses of forward rates and expected short rates to different shocks make it difficult to use the forward rate as a reliable indicator of future monetary policy.

Given the difficulties discussed above, an alternative way to obtain indicators of future monetary policy is using term structure information, in addition to the forward rate, and macroeconomic information that may be available to policy makers. Here we consider the case of representing expected future one-period rates in terms of the current level of the rate, the forward rate and lagged inflation. Figure 3 contains the loading coefficients of functions of the form

$$
\mathbb{E}_{t}\left[i_{t+n}\right]=\alpha_{n}+\beta_{i, n} i_{t}+\beta_{f, n} f_{t, n}+\beta_{\pi, n} \pi_{t-1} .
$$

Under the expectations hypothesis, the loading coefficient on the forward rate $\left(\beta_{f, n}\right)$ is 1 and zero for the other two explanatory variables. The existence of time-varying term premia makes these coefficients to depend on the weight of inflation on the policy function. Panel B of the figure shows that the loading coefficients on the forward rates are different from 1 . In the $\rho$-economy, term premia are more volatile than under the $\rho_{\text {low }}$-economy and for that reason the correlation between the forward rate and expected future short-rates is lower. Therefore, for short-term horizons the current level of the short-term rate and lagged inflation have important explanatory power about future monetary policy when the weight of inflation is high. However, this explanatory power decreases with maturity and tend to be very similar to that under the low inflation weight for long-term maturities. As a result, a policy maker that is conservative with respect to inflation 
Panel A: Loading on the Short Rate

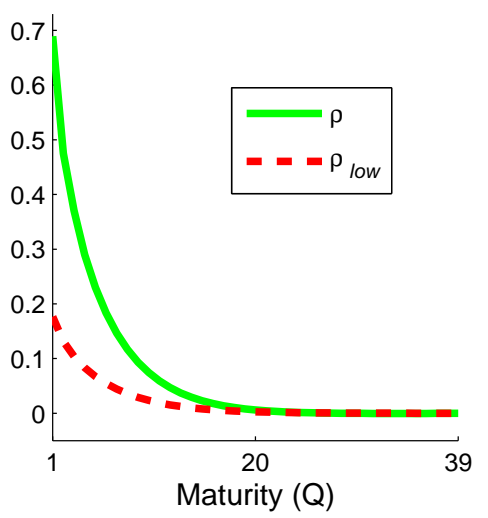

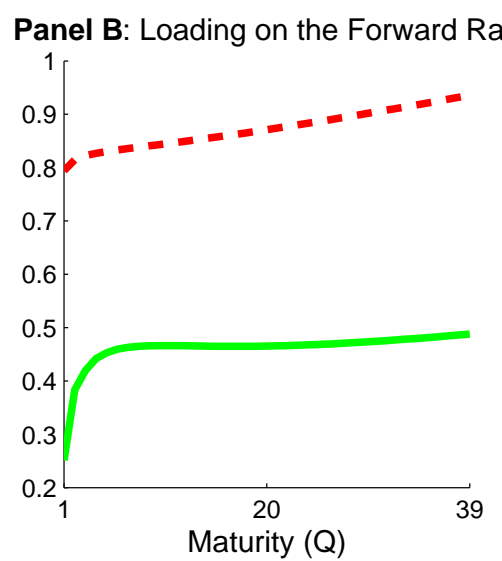

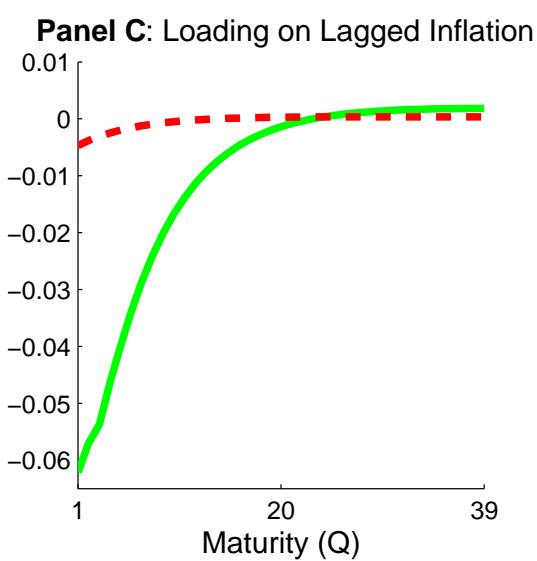

Figure 3: Loading coefficients for the regression $i_{t+n}=\alpha_{n}+\beta_{i, n} i_{t}+\beta_{f, n} f_{t, n}+\beta_{\pi, n} \pi_{t-1}+\varepsilon_{f, t+n}$ for one-period forward rates of different horizons.

should not rely only on the forward rate to predict changes in expectations of future monetary policy for short horizons but also should pay attention to other indicators as, for instance, the current level of the short-term rate. For longer horizons the forward rate is a useful indicator for future monetary policy independently of how conservative is the monetary authority.

\subsubsection{The Economic Content of the Term Structure}

Section 3.3 shows that the term structure of interest is a rich source of macroeconomic information that, however, is not easy to extract. In this section we examine the model implications of considering expected inflation simply as the difference between the nominal and the real interest rate. We also analyze how the economic content of different maturity sectors of the yield curve and their predictive power are affected by the weight that the monetary authority gives to inflation in the policy function.

\section{The Term Structure of Real Interest Rates}

As shown in equation (21), time-varying term premia make it difficult to extract expected future inflation from the yield curve. It is useful to compute the model-implied term structure of real interest rates and decompose the difference between nominal and interest rates into their expected inflation and term premium components. This decomposition allows us to observe the possible mistakes involved in using the difference between nominal and real rates as indicator of future inflation.

The real term structure is an affine term structure of the class presented in section 2.3. The characterization of the associated real stochastic discount factor is presented in Proposition 2. 
Proposition 2. The real pricing kernel $M_{t, t+1}^{\text {real }}$ can be represented by equations (12) and (13) and the parameterization for the state variables in Proposition 2 when

$$
\mathbf{s}_{t} \equiv\left(\Delta c_{t}^{n a t}, \pi_{t}, \pi_{t-1}\right)^{\top}
$$

and

$$
\begin{gathered}
\Gamma_{0}^{\text {real }}=-\log \beta+\gamma\left(1-\phi_{c}\right) \theta_{c}-\gamma \rho\left(1-\phi_{\epsilon}\right) \delta_{\pi}-\frac{1}{2} \gamma^{2} \sigma_{\mu}^{2}, \\
\Gamma_{1}^{r e a l}=\left[\begin{array}{c}
\gamma\left(\phi_{c}-\eta \sigma_{\mu}^{2}\right) \quad\left(1-\phi_{\epsilon}+\eta \sigma_{\mu}^{2}\right) \gamma \rho-\eta \rho \gamma \sigma_{\mu}^{2}
\end{array}\right]^{\top}, \\
\lambda_{0}^{\text {real }}=\gamma\left(\begin{array}{c}
1 \\
-\rho
\end{array}\right), \quad \lambda_{1}^{\text {real }}=\lambda_{1}, \quad \text { and } \quad \sigma_{\mu}^{2}=\sigma_{c}^{2}+\rho^{2} \delta_{\epsilon}^{2} \sigma_{\epsilon}^{2} .
\end{gathered}
$$

A comparison of the coefficients in propositions 1 and 2 is helpful to understand the differences between the real and nominal pricing kernels. The absence of inflation in the real pricing kernel eliminates not only a constant precautionary savings motive for inflation but also a term capturing the correlation between inflation and consumption growth. In addition, the constant component of the price of risk $\lambda_{0}^{\text {real }} \neq \lambda_{0}$. However, this component is still sensitive to inflation given the fact that consumption growth is negatively correlated with inflation. The sensitivity depends then on $\rho$. It is important to note, however, that the time varying component of the market price of risk is the same as for the nominal pricing kernel. It is the case, since the variability of the price of risk is entirely driven by the preference shock.
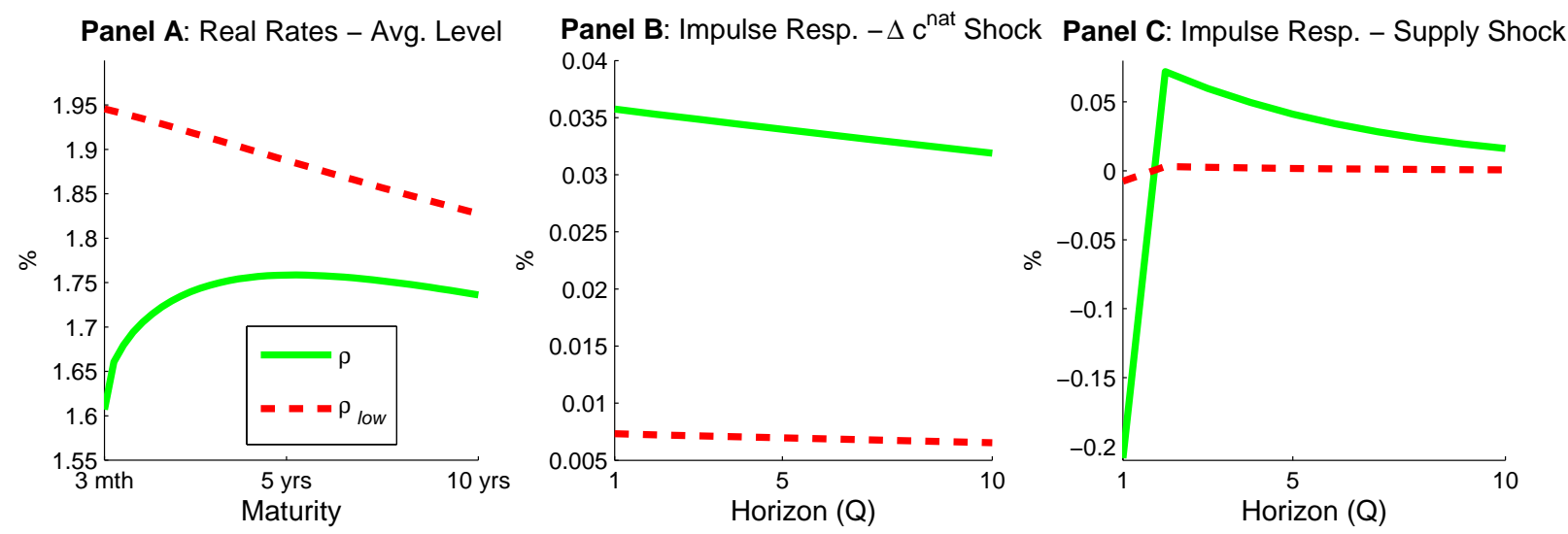

Figure 4: Real Interest Rates and Impulse Responses of the difference $i_{t}-r_{t}-\mathbb{E}_{t}\left[\theta_{\pi}+\pi_{t+1}\right]$.

Now we can analyze the differences between the nominal and real term structures. Panel A of Figure 4 shows the real term structures for the two model economies. While the real yield curve is upward sloping when the weight of inflation is high, it becomes downward sloping when the output 
gap gains relative importance in the policy function. It implies that a policy that pays significant attention to the stabilization of the output gap reduces the sources of real risk and agents perceive long-term real bonds as low-risk instruments. However, if the monetary authority becomes more conservative about inflation, consumption growth is less correlated to natural consumption growth and this deviation represents a real risk that translates into positive expected excess returns in long-term real bonds. Additionally, Figure 11 in the appendix shows the difference between the average nominal rates and the sum of the average real rates and unconditional expected inflation. For the one-period interest rates, the difference is high (more than 40 bps.) when the inflation weight in the policy function is high and it becomes small if the monetary authority reduces the weight on inflation. Therefore, the significant amount of term premia in nominal and real rates when the monetary authority is more conservative about inflation makes the difference between the nominal and real rate a poor indicator of one-period ahead inflation.

It is also useful to observe how economic shocks affect the difference between the nominal rate and the real rate plus expected inflation. Panels $\mathrm{B}$ and $\mathrm{C}$ of Figure 4 contain impulses responses to a shock to natural consumption growth and a supply shock, respectively. The difference is more sensitive to the shocks when monetary policy is more conservative about inflation. A shock to the natural rate of consumption has effects that die out slowly but, at the same time, the magnitude of the effect is small even for a high inflation weight. This is no longer true for a supply shock. A positive supply shock initially reduces the difference between the nominal rate and the real rate plus expected inflation. The initial reaction is followed by an increase in the difference that disappears over time. The effect is highly amplified by a high weight of inflation in the policy function and can produce a significant initial reduction in the difference (20 bps. in the graph). The reason for the reduction is the big impact of the supply shock on the output gap as a result of the targeting policy. The subsequent amplification in the difference is the result of the dependence of term premia on changes in the output gap rather than the level of the output gap. Then, the initial reduction produced by the supply shock is offset by the lagged effect one period after. To summarize, when monetary policy pays significant attention to price stabilization, expected inflation becomes more difficult to extract from the yield curve given the increased variability in term premia.

\section{Predictability of Macro Variables and the Expectations Hypothesis}

Forward-looking economic agents use long-term bonds to implement consumption and investment contingent plans over time. As a result, long-term interest rates can be useful to predict future economic activity. As shown in equation (19), long-term rates can be seen as risk-adjusted expectations of future short-term rates. Then, it is helpful to ask whether any predictability of interest rates comes from their expectations hypothesis or term premium components, and how this predictability is affected by the inflation weight in the policy objective function. 

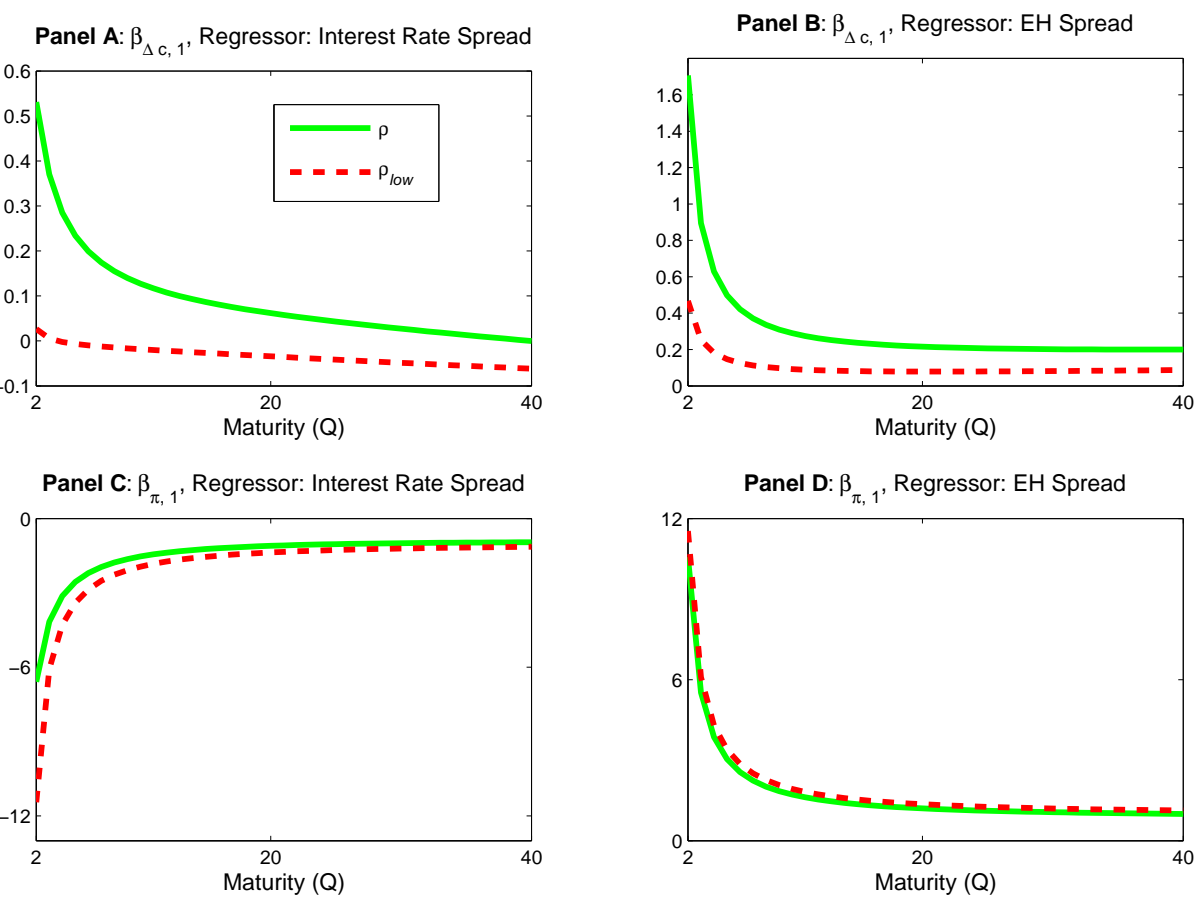

Figure 5: Slope coefficients for univariate regressions $m v_{t+1}=\alpha_{m v, 1}+\beta_{m v, 1}\left(i_{t}^{(n)}-i_{t}\right)+\varepsilon_{m v, t+1}$ for $m v=\{\Delta c, \pi\}$. The regressor is the interest rate spread or its expectations hypothesis component for different maturities.

Consider univariate regressions of the type described by equation (22), where the regressor is the term spread or its expectations hypothesis component. The comparison of these two regressions provides an idea of the role of term premia in the predictability of future economic conditions. Figure 5 presents the slope coefficients for this type of regressions for consumption growth and inflation one period ahead. The regressions are run for spreads of different maturities. Panels A and B show that the predictive power of spreads about future consumption growth depends on the type of monetary policy that is conducted. A policy paying significant attention to price stability involves greater predictive ability of the term structure than a policy which assigns more weight to output gap deviations. The reason is the existence of persistent output gaps when the inflation weight is high. It can also be seen that the predictive power declines with maturity. The differences in the magnitude of the coefficients between the term spread and its expectations hypothesis component show that the time-varying term premia in interest rates reduce the predictive power for consumption growth. The $R^{2}$ 's for the regressions in Figure 12 in the appendix show the low ability of spreads to explain the variability of consumption growth.

With respect to the predictability of inflation, Panels $\mathrm{C}$ and D of Figure 5 show small differences between policies with high or low weight on inflation. However, the directions predicted by 
the spread and its expectations hypothesis are different. While a positive spread predicts deflation (relative to the trend), the related expectations hypothesis component predicts positive inflation. It suggests a risk premium component in interest rates that entirely shifts the predictive ability of the yield curve with respect to inflation. That is, positive expected excess return signal low inflation in the future. Figure 12 in the appendix show that term-spreads explain a significant fraction of the variability of inflation. This fraction is affected by the weight of inflation in the policy function for short-term spreads. A high weight reduces the explanatory power of spreads.

Predictive Power of the Yield Curve. Short-Term Rate vs. Term Spreads

It is also natural to ask whether the one-period interest rate has more predictive power of future economic conditions than term spreads. This question can be approached running bivariate regressions where the regressors are the one-period rate and a term spread. Figure 6 presents the slope coefficients for this type of regressions for consumption growth and inflation using yields of different maturities. The one-period nominal rate has important explanatory power for future
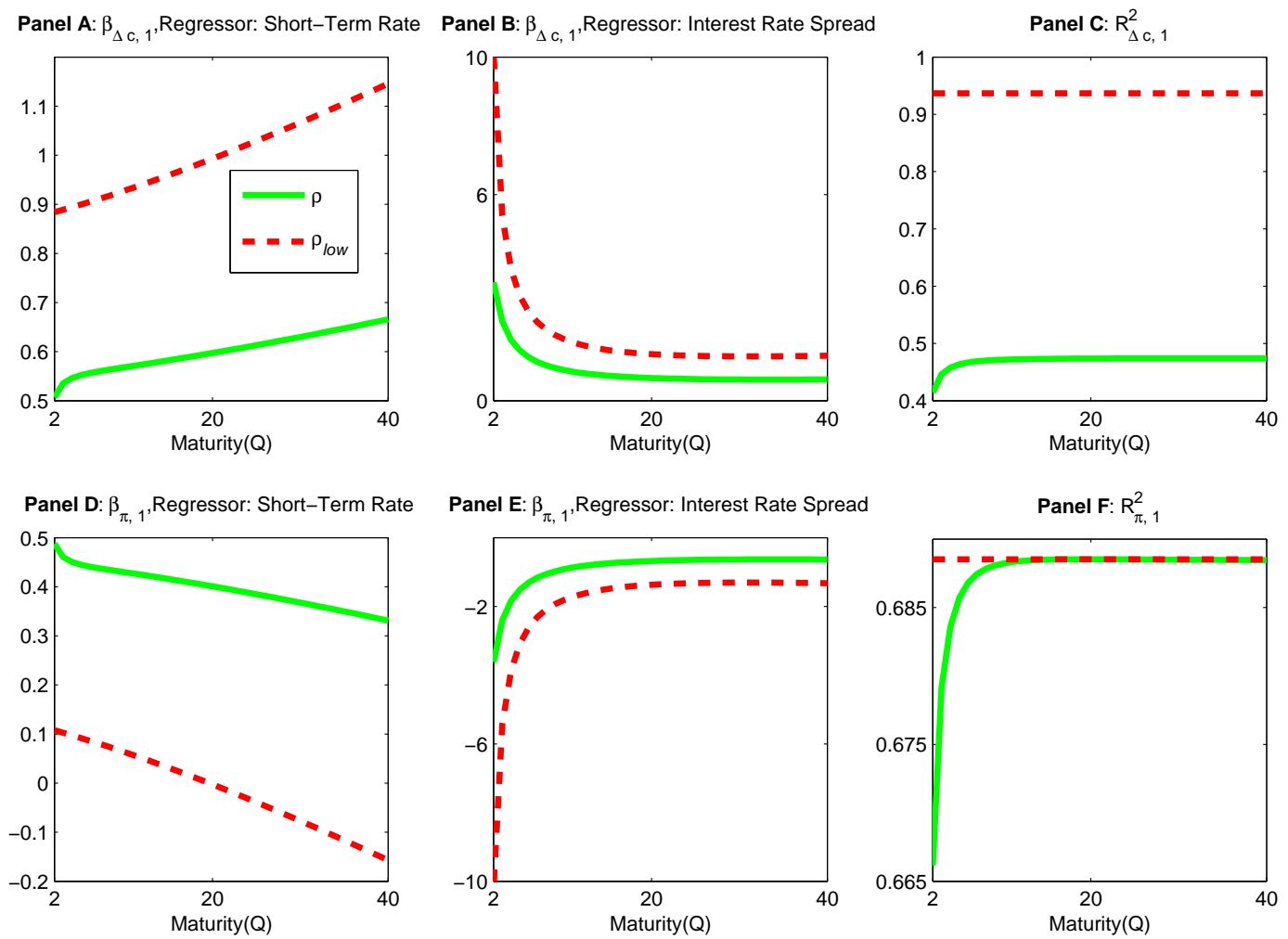

Figure 6: Slope coefficients for bivariate regressions $m v_{t+1}=\alpha_{m v, 1}+\beta_{m v, 1,1} i_{t}+\beta_{m v, 1,2}\left(i_{t}^{(n)}-\right.$ $\left.i_{t}\right)+\varepsilon_{m v, t+1}$ for $m v=\{\Delta c, \pi\}$. The regressors are the one-period interest rate and the term spread for different maturities.

consumption growth and inflation as can be inferred from Panels $\mathrm{C}$ and $\mathrm{F}$ in the figure. This 
power depends on the type of monetary policy that is conducted. In particular, the $R^{2}$ 's for the consumption growth regressions are significantly lower in the $\rho$-economy than in the $\rho_{\text {low }}{ }^{-}$ economy. Also, the loadings on the short rate for the consumption growth regressions are smaller than in the $\rho_{l o w}$-economy and tend to increase with the maturity of the term spread. The loadings on the short rate for the inflation-related regressions are higher when the inflation weight in the policy function is high. In summary, the current level of the one-period interest rate contains considerable amount of information about consumption growth one period ahead, which is not contained in spreads. It does not add much information about future inflation that is not already provided by the spread.

\section{Extracting Current Consumption Growth and Inflation from Interest Rates}

The economic model implies that the current values for consumption growth and inflation can be obtained from term structure information without error. This possibility can be seen as a useful tool for policy makers that have to make decisions in an environment where macroeconomic data are collected and processed with a lag and may involve some noise. Figure 7 shows the coefficients of representations of consumption growth and inflation in terms of the short-term

rate, term spreads and lagged inflation. Lagged inflation was chosen for simplicity given that it is part of the original set of state variables. It can be replaced with another lagged value of a macro variable or with an additional interest rate spread or a linear combination of spreads. Qualitatively, the implications are similar to those for the predictability of macro variables one period ahead. In particular, the presence of a third state variable (lagged inflation in this case) is helpful to obtain the value of consumption growth when the weight of inflation in the policy function is high ( $\rho$-economy). It is due to the lack of enough explanatory power of the short-term rate and one spread under these circumstances.

\subsubsection{Policy Rules}

Section 3.4 describes how the equilibrium one-period interest rate can be written in terms of different macroeconomic and term structure information. It also suggests considering the equilibrium rate as a policy rule to implement the optimal monetary policy associated with the objective function (2). We analyze here different policy rules that react to macroeconomic and term structure information for the two model economies (high and low inflation weight in the objective function). We characterize first a rule that reacts only to macroeconomic variables for an initial comparison of the policies in the two model economies. Then we evaluate four different types of rules: rules that only respond to term spreads, rules that react to both macro variables and interest rates, rules that respond to a lagged short-term rate, current spreads and lagged inflation and, finally, rules with interest rate smoothing.

\section{A Macroeconomic Rule}



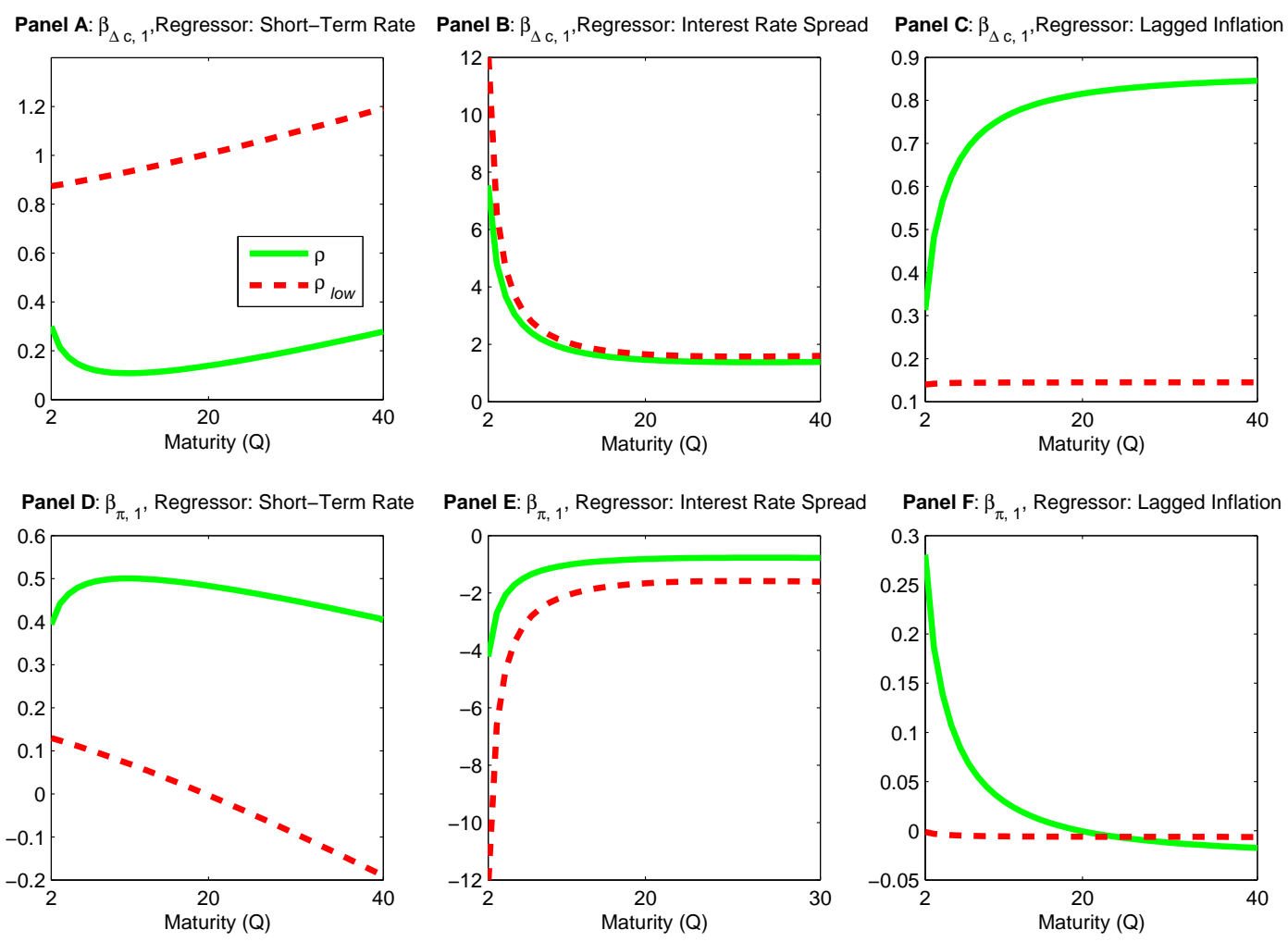

Figure 7: Loading coefficients for $m v_{t}=\alpha_{m v, 0}+\beta_{m v, 0,1} i_{t}+\beta_{m v, 0,2}\left(i_{t}^{n)}-i_{t}\right)+\beta_{m v, 0,3} \pi_{t-1}$ for $m v=\{\Delta c, \pi\}$. The explanatory variables are the one-period interest rate, the term spread for different maturities and lagged inflation.

Table 3 contains the coefficients of a rule that sets the one-period rate responding to consumption growth and the current and lagged levels of inflation. The rules for the two economies assign positive coefficients to consumption growth and current inflation and a negative coefficient to lagged inflation. However, the coefficients for inflation are higher when the monetary authority is more conservative about inflation. This is consistent with the empirical evidence presented in Clarida, Galí and Gertler (2000) describing monetary policy during the period when Paul Volcker and Alan Greenspan were chairmen of the Federal Reserve System.

Table 3: Coefficients for the Macroeconomic Rules - High an Low Inflation Weight Economies

\begin{tabular}{ccccc}
\hline Economy & Constant & $\Delta c_{t}$ & $\pi_{t}$ & $\pi_{t-1}$ \\
\hline$\rho$ & 0.0416 & 0.9971 & 1.7821 & -0.8122 \\
$\rho_{\text {low }}$ & 0.0416 & 0.9969 & 0.9920 & -0.1383 \\
\hline
\end{tabular}

A Term Structure Rule 
The macroeconomic rule presented above can be written in terms of interest rate spreads. Table 4 shows the coefficients of a rule that reacts to three different sectors of the term structure: the two-year, five-year and ten-year spreads. The rules for the $\rho$ and $\rho_{l o w}$ economies are qualitatively the same. There are negative reactions to the short and long ends of the curve (2 and 10 year spreads) and a positive reaction to the 5-year spread. Quantitatively, the rule when the policy is more conservative about inflation implies stronger reactions to the three sectors of the curve.

Table 4: Coefficients for the Term Structure Rules - High an Low Inflation Weight Economies

\begin{tabular}{ccccc}
\hline Economy & Constant & $i_{t}^{(8)}-i_{t}$ & $i_{t}^{(20)}-i_{t}$ & $i_{t}^{(40)}-i_{t}$ \\
\hline$\rho$ & 0.0709 & -5.0748 & 14.4206 & -10.4906 \\
$\rho_{\text {low }}$ & 0.0578 & -4.2440 & 13.0671 & -9.9480 \\
\hline
\end{tabular}

\section{A Macroeconomic and Term Structure Rule}

We can also analyze a representation for the short-term rate that combines macroeconomic and term structure information. This type of representations are useful to understand what type of information can be captured by the term structure that is not already contained in the macroeconomic variables that are part of the policy rule. Figure 8 shows the coefficients for policy rules that react to consumption growth, an interest rate spread and lagged inflation, using different maturities for the spread. This rules can be compared against the macroeconomic rule presented above, to see how replacing current inflation with a term spread affects a policy rule. The figure shows that the implied rules under the $\rho$-economy are much more sensitive to the variables than rules for the $\rho_{l o w}$-economy. For the $\rho$-economy the coefficient for consumption
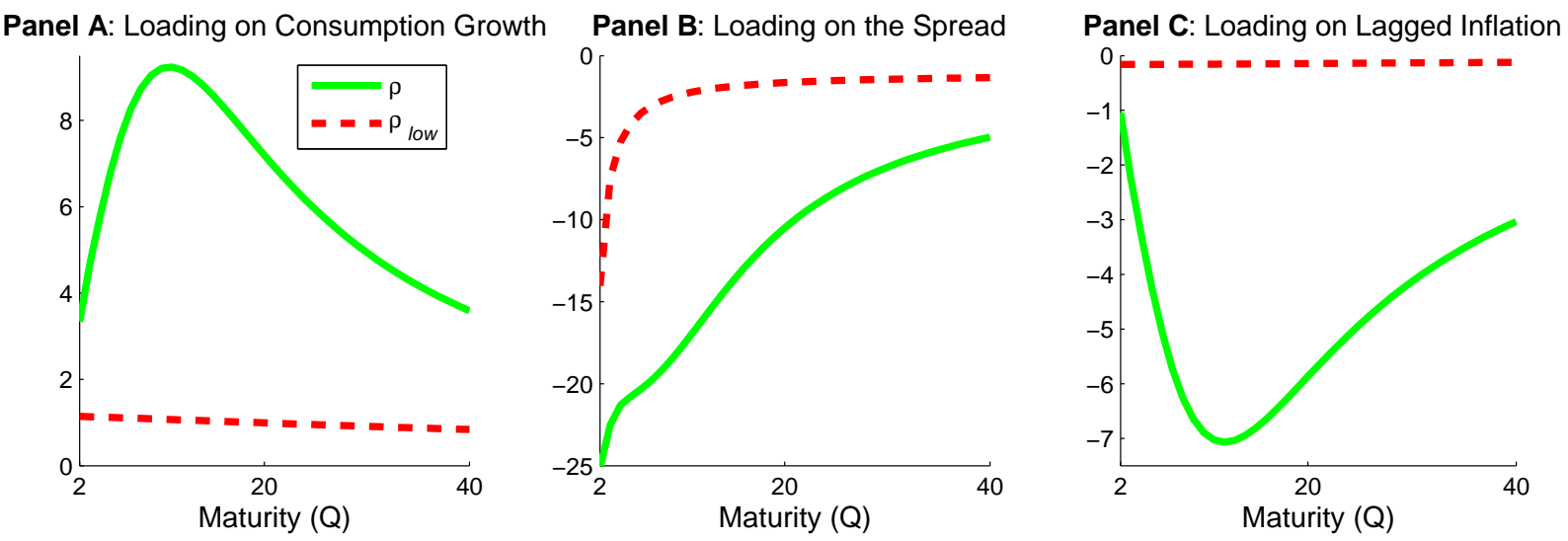

Figure 8: Loading coefficients for a policy rule that reacts to consumption growth, an interest-rate spread and lagged inflation, for different spread maturities. 
growth increases significantly when a spread with intermediate maturity is used, but for longer maturities the coefficient decreases. When the weight of inflation is low, the coefficients do not vary significantly with the maturity of the spread. The coefficients of the spreads are negative and increase (less negative) with maturity. While the spread coefficients get closer to zero quickly with maturity when the weight of inflation is low in the policy function, they are important describing the short-term rate when the weight of inflation is high. This difference in the sensitivity of the policy rule to the spreads in the two economies is related to the fact that long-term rates are more volatile in the $\rho$-economy.

\section{A Policy Rule with Interest Rate Smoothing}

Equation (24) shows us that it is possible to represent the equilibrium short-term rate depending on its one-lag value, an interest-rate spread and some error terms. This suggests a policy rule that smooths interest rates over time. Figure 9 shows the coefficients for the lagged interest rate and the spread for this type of rules using different maturities for the spread. The loadings on the
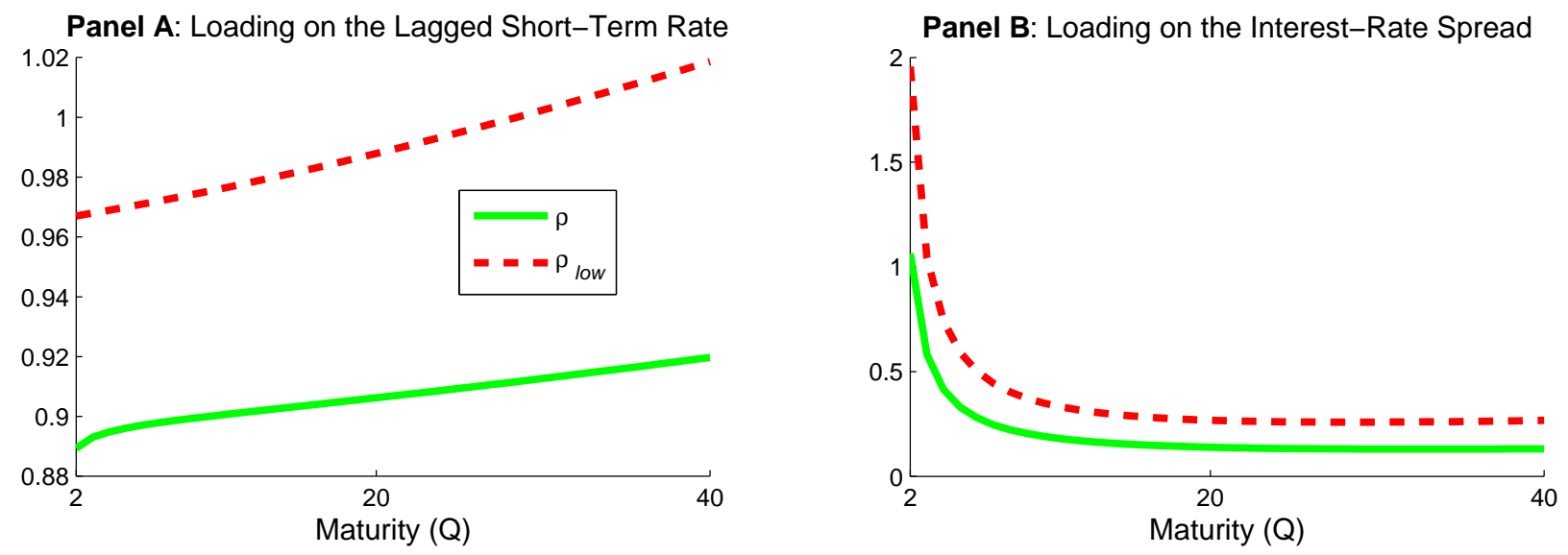

Figure 9: Loading coefficients for a policy rule that reacts to the one-period lagged short-term rate and an interest-rate spread, for different spread maturities.

lagged value for the interest rate and the spread are positive. While the loading on the interest rate increases with the maturity of the spread the loading on the spread decreases. Therefore, the information that spreads contain about the short-term rate declines with the maturity of the spread in this representation. A reduction in the weight of inflation in the policy objective function increases the lagged interest rate loading to levels that can be greater than one for some spreads. It can also be seen that using short-term spreads the loading on the spread in the $\rho$ economy is significantly higher than in the low inflation weight economy. However, the differences die out fast as longer maturities are used in the rule. 


\section{Conclusion}

The study of the economic information contained in the term structure of interest rates is of great importance for policy makers who require tools to understand current economic conditions and make appropriate decisions. This analysis is far from simple given the existence of time-varying risk premia in interest rates and the possible dependence of the term structure on the actual monetary policy regime. This chapter studies the economic content of interest rates using a general equilibrium theory of the term structure. The equilibrium model incorporates monetary policy and implies term premia that vary over time. Monetary policy has real effects and is conducted to maximize a welfare-related measure. It is shown that the economic content of the yield curve may depend considerably on the monetary policy regime. The power of interest rates to predict future monetary policy, real economic activity and inflation is highly sensitive to the weight that the monetary authority assigns to inflation and output stabilization on the policy objective. A high inflation weight allows greater instability in output and thus increases the compensation for real risk in nominal interest rates.

This paper also shows that an optimal monetary policy can be implemented through interestrate rules that react to term structure information. These rules offer informational advantages over macroeconomic rules and might involve welfare benefits. The particular way in which the short-term rate should respond to term structure information in the policy rule depends on the policy regime. For instance, a policy rule with an interest-rate smoothing motive that reacts to interest rate spreads has reaction coefficients that are lower when the monetary authority is more conservative about inflation than about output stabilization.

Finally, this paper presents an interesting link between welfare and term premia that deserves further study. Certain type of welfare-improving policies can be implemented under discretion by raising the weight of inflation in the policy function. These policies may increase the real risk in the economy and the compensation for this risk in long-term rates. Therefore, lower and more stable long-term rates do not always imply higher economic welfare. 


\section{References}

Ang, Andrew and Monika Piazzesi. 2003. "A No-Arbitrage Vector Autoregression of the Term Structure Dynamics with Macroeconomic and Latent Variables." Journal of Monetary Economics 50(4):745-787.

Backus, David, Silverio Foresi and Chris Telmer. 1998. "Discrete-Time Models of Bond Pricing." National Bureau of Economic Research Working Paper.

Campbell, John Y. and Robert J. Shiller. 1991. "Yield Spreads and Interest Rates: A Bird's Eye View." Review of Economic Studies 58:495-514.

Clarida, Richard, Jordi Galí and Mark Gertler. 1999. "The Science of Monetary Policy: A New Keynesian Perspective." Journal of Economic Literature 37:1661-1707.

Clarida, Richard, Jordi Galí and Mark Gertler. 2000. "Monetary Policy Rules and Macroeconomic Stability: Evidence and Some Theory." The Quarterly Journal of Economics pp. 147-180.

Cochrane, John H. 2006. "Identification and Price Determination with Taylor Rules: A Critical Review." University of Chicago Working Paper.

Dai, Qiang and Kenneth J. Singleton. 2002. "Expectations Puzzles, Time-Varying Risk Premia, and Affine Models of the Term Structure." The Journal of Financial Economics 63:405-443.

Duffee, Gregory R. 2002. "Term Premia and Interest Rate Forecasts in Affine Models." Journal of Finance 57(1):405-443.

Duffie, Darrell and Rui Kan. 1996. "A Yield-Factor Model of Interest Rates." Mathematical Finance (6):379-406.

Estrella, Arturo. 2005. "Why Does the Yield Curve Predict Output and Inflation?" The Economic Journal 115(505):722-744.

Estrella, Arturo and Gikas A. Hardouvelis. 1991. "The Term Structure as a Predictor of Real Economic Activity." Journal of Finance 46(2):555-576.

Fama, Eugene F. and Robert R. Bliss. 1987. "The information in Long-Maturity Forward Rates." The American Economic Review 77:680-692.

Gallmeyer, Michael, Burton Hollifield and Stanley Zin. 2005. "Taylor Rules, McCallum Rules and the Term Structure of Interest Rates." Journal of Monetary Economics, forthcoming.

Goodfriend, Marvin. 1998. "Using the Term Structure of Interest Rates for Monetary Policy." Federal Reserve Bank of richmond Economic Quarterly 84(3):13-30. 
Kydland, Finn E. and Edward C. Prescott. 1977. "Rules rather than Discretion: The Inconsistency of the Optimal Plan." Journal of Political Economy 85:473-490.

McCallum, Bennett. 1999. "Issues in the Design of Monetary Policy Rules." in J.B. Taylor and M. Woodford eds, Handbook of Macroeconomics 1.

Orphanides, Athanasios. 2001. "Monetary Policy Rules Based on Real-Time Data." American Economic Review 91:964-985.

Piazzesi, Monika and Martin Schneider. 2006. "Equilibrium Yield Curves." 2006 NBER Macroeconomics Annual, forthcoming.

Rotemberg, Julio and Michael Woodford. 1999. "Interest Rate Rules in a Estimated Sticky Price Model." Monetary Policy Rules . Edited by John B. Taylor, Chicago University Press.

Svensson, Lars E.O. 1994. "Estimating and Interpreting Forward Rates: Sweden 1992- 4." National Bureau of Economic Research Working Paper \#4871.

Taylor, John. 1993. "Discretion versus Policy Rules in Practice." Carnegie-Rochester Conferences Series on Public Policy 39:195-204.

Woodford, Michael. 2003. Interest and Prices. New Jersey: Princeton University Press. 


\section{Appendix}

\section{A Term-Structure-Based Policy Rule with Interest Rate Smooth- ing}

The original set of state variables $\mathbf{s}_{t} \equiv\left(\Delta c_{t}^{(n)}, \pi_{t}, \pi_{t-1}\right)$ contains two contemporaneous values and one lagged valued. Consider the reduced set of contemporaneous state variables $\mathbf{s}_{t}^{r} \equiv\left(\Delta c_{t}^{(n)}, \pi_{t}\right)$, with process

$$
\mathbf{s}_{t+1}^{r}=\left(\mathbb{I}_{2 \times 2}-\Phi_{r}\right) \theta_{r}+\Phi_{r} \mathbf{s}_{t}^{r}+\Psi_{r}^{\top} \Sigma^{1 / 2} \varepsilon_{t+1},
$$

where $\Phi_{r}=\operatorname{diag}\left\{\phi_{c}, \phi_{\epsilon}\right\}, \theta_{r}=\left(\theta_{c}, \delta_{\pi}\right)^{\top}$ and $\Psi_{r}=\operatorname{diag}\left\{1, \delta_{\epsilon}\right\}$. The one-period interest rate and a term spread for some maturity can be represented by $\mathbf{s}_{t}^{r}$ in the system

$$
\begin{aligned}
\left(\begin{array}{c}
i_{t} \\
i_{t}^{(n)}-i_{t}
\end{array}\right) & =\left(\begin{array}{c}
\mathcal{A}_{1} \\
\frac{1}{n} \mathcal{A}_{n}-\mathcal{A}_{1}
\end{array}\right)+\left[\begin{array}{cc}
\mathcal{B}_{1}^{\top} e_{1} & \mathcal{B}_{1}^{\top} e_{2} \\
\left(\frac{1}{n} \mathcal{B}_{n}-\mathcal{B}_{1}\right)^{\top} e_{1} & \left(\frac{1}{n} \mathcal{B}_{n}-\mathcal{B}_{1}\right)^{\top} e_{2}
\end{array}\right] \mathbf{s}_{t}^{r} \\
& +\left[\begin{array}{cc}
0 & \mathcal{B}_{1}^{\top} e_{3} \\
0 & \left(\frac{1}{n} \mathcal{B}_{n}-\mathcal{B}_{1}\right)^{\top} e_{3}
\end{array}\right] \mathbf{s}_{t-1}^{r}=\mathbb{K}+\mathbb{L} \mathbf{s}_{t}^{r}+\mathbb{M} \mathbf{s}_{t-1}^{r} \\
& =\mathbb{K}+\mathbb{L}\left(\mathbb{I}_{2 \times 2}-\Phi_{r}\right) \theta_{r}+\left(\mathbb{L} \Phi_{r}+\mathbb{M}\right) \mathbf{s}_{t-1}^{r}+\mathbb{L} \Psi_{r}^{\top} \Sigma^{1 / 2} \varepsilon_{t} \\
& =\tilde{\mathcal{C}}+\tilde{\mathcal{D}} \mathbf{s}_{t-1}^{r}+\mathcal{H} \varepsilon_{t}
\end{aligned}
$$

Therefore, if $\tilde{\mathcal{D}}$ is an invertible matrix, the reduced set of state variables can be written in terms of the short-term rate and the term spread as

$$
\mathbf{s}_{t-1}^{r}=\tilde{\mathcal{D}}^{-1}\left[\left(\begin{array}{c}
i_{t} \\
i_{t}^{(n)}-i_{t}
\end{array}\right)-\tilde{\mathcal{C}}-\mathcal{H} \varepsilon_{t}\right]
$$

Replacing it into equation (26) and then into equation (27) again, we obtain the partitioned representation

$$
\left(\begin{array}{c}
i_{t} \\
i_{t}^{(n)}-i_{t}
\end{array}\right)=\left[\begin{array}{c}
\mathcal{F}_{1} \\
\mathcal{F}_{2}
\end{array}\right]+\left[\begin{array}{cc}
\mathcal{G}_{11} & \mathcal{G}_{12} \\
\mathcal{G}_{21} & \mathcal{G}_{22}
\end{array}\right]\left(\begin{array}{c}
i_{t-1} \\
i_{t-1}^{(n)}-i_{t-1}
\end{array}\right)+\left[\begin{array}{c}
\mathcal{H}_{1_{(1 \times 2)}} \\
\mathcal{H}_{2_{(1 \times 2)}}
\end{array}\right] \varepsilon_{t}+\left[\begin{array}{c}
\mathcal{I}_{1_{(1 \times 2)}} \\
\mathcal{I}_{2_{(1 \times 2)}}
\end{array}\right] \varepsilon_{t-1},
$$

where

$$
\begin{gathered}
{\left[\begin{array}{c}
\mathcal{F}_{1} \\
\mathcal{F}_{2}
\end{array}\right]=\tilde{\mathcal{C}}+\tilde{\mathcal{D}}\left(\mathbb{I}_{2 \times 2}-\Phi_{r}\right) \theta_{r}-\tilde{\mathcal{D}} \Phi_{r} \tilde{\mathcal{D}}^{-1} \tilde{\mathcal{C}}, \quad\left[\begin{array}{ll}
\mathcal{G}_{11} & \mathcal{G}_{12} \\
\mathcal{G}_{21} & \mathcal{G}_{22}
\end{array}\right]=\tilde{\mathcal{D}} \Phi \tilde{\mathcal{D}}^{-1}} \\
\text { and }\left[\begin{array}{c}
\mathcal{I}_{1} \\
\mathcal{I}_{2}
\end{array}\right]=\tilde{\mathcal{D}}\left(\mathbb{I}_{2 \times 2}-\Phi_{r} \tilde{\mathcal{D}}^{-1} \mathbb{L}\right) \Psi_{r}^{\top} \Sigma^{1 / 2} .
\end{gathered}
$$


If $\mathcal{G}_{22} \neq 0$, the inferior partition allows us to write the lagged spread in terms of the current spread, the lagged short-term rate and some errors. Replacing that representation for the lagged spread into the superior partition, we obtain the interest-rate smoothing representation (24) for the one-period rate.

\section{B Model-Implied Moments and Calibration Details}

Let $\pi_{t}^{\text {total }}=\theta_{\pi}+\pi_{t}$ be the level of inflation. The moments that were considered for the calibration are presented in Table 5 .

Table 5: Analytical Characterization of Some Model-Implied Statistics

\begin{tabular}{l|l}
\hline & \\
$\mathbb{E}\left[\pi_{t}^{\text {total }}\right]=\theta_{\pi}+\delta_{\pi}$ & $\mathbb{E}\left[\Delta c_{t}\right]=\mathbb{E}\left[\Delta c_{t}^{n}\right]=\theta_{c}$ \\
$\operatorname{var}\left(\pi_{t}^{\text {total }}\right)=\operatorname{var}\left(\pi_{t}\right)=\delta_{\epsilon}^{2} \operatorname{var}\left(\epsilon_{t}\right)$ & $\operatorname{var}\left(\Delta c_{t}\right)=\operatorname{var}\left(\Delta c_{t}^{n}\right)+2 \rho^{2}\left(1-\phi_{\epsilon}\right) \operatorname{var}\left(\pi_{t}\right)$ \\
$\operatorname{cov}\left(\pi_{t}^{\text {total }}, \pi_{t-1}^{\text {total }}\right)=\operatorname{cov}\left(\pi_{t}, \pi_{t-1}\right)=\phi_{\epsilon} \operatorname{var}\left(\pi_{t}\right)$ & $\operatorname{cov}\left(\Delta c_{t}, \Delta c_{t-1}\right)=\phi_{c} \operatorname{var}\left(\Delta c_{t}\right)-\rho^{2}\left(1-\phi_{\epsilon}\right)^{2} \operatorname{var}\left(\pi_{t}\right)$ \\
$\operatorname{cov}\left(\Delta c_{t}, \pi_{t}^{\text {total }}\right)=-\rho\left(1-\phi_{\epsilon}\right) \operatorname{var}\left(\pi_{t}\right)$ & $\operatorname{var}\left(\Delta c_{t}^{n}\right)=\frac{\sigma_{c}^{2}}{1-\phi_{c}^{2}}$ \\
$\operatorname{var}\left(\epsilon_{t}\right)=\frac{\sigma_{\epsilon}^{2}}{1-\phi_{\epsilon}^{2}}$ & \\
& \\
\hline
\end{tabular}

There are 12 parameters involved in the calibration: $\beta, \gamma, \eta, \phi_{c}, \theta_{c}, \sigma_{c}, \phi_{\epsilon}, \sigma_{\epsilon}, \kappa, \rho, x^{s t a r}, \theta_{\pi}$. The value for the parameters $(x)$ in the calibration are denoted by $\hat{x}$ and the sample values for the statistics $(y)$ are denoted by $\tilde{y}$.

Let $\hat{x}^{*}=0$, then $\hat{\delta}_{\pi}=0$ and $\hat{\theta}_{\pi}=\tilde{\mathbb{E}}\left[\pi_{t}^{\text {total }}\right]$. The other parameters were selected to match the moments presented above. Then,

$$
\begin{gathered}
\hat{\theta}_{c}=\tilde{\mathbb{E}}\left[\Delta c_{t}\right], \quad \hat{\phi}_{\epsilon}=\frac{\operatorname{cõv}\left(\pi_{t}^{t o t a l}, \pi_{t-1}^{t o t a l}\right)}{\operatorname{vãr}\left(\pi_{t}^{t o t a l}\right)}, \\
\hat{\rho}=-\frac{1}{1-\hat{\phi}_{\epsilon}} \frac{\operatorname{cõv}\left(\Delta c_{t}, \pi_{t}^{t o t a l}\right)}{\operatorname{vãr}\left(\pi_{t}^{t o t a l}\right)}, \\
\hat{\phi}_{c}=\frac{1}{\operatorname{vãr}\left(\Delta c_{t}^{n}\right.}\left[\operatorname{cõv}\left(\Delta c_{t}, \Delta c_{t-1}\right)+\hat{\rho}^{2}\left(1-\hat{\phi}_{\epsilon}\right)^{2} \operatorname{vãr}\left(\pi_{t}^{t o t a l}\right)\right], \\
\hat{\sigma}_{\epsilon}^{2}=\left(1-\hat{\phi}_{\epsilon}^{2}\right)\left(1-\hat{\beta} \hat{\phi}_{\epsilon}+\hat{\rho} \hat{\kappa}\right)^{2} \operatorname{vãr}\left(\pi_{t}^{\text {total }}\right)
\end{gathered}
$$


where $\hat{\beta}$ is found to match the one-period interest rate as follows:

$$
\begin{aligned}
\log \hat{\beta} & =-\tilde{\mathbb{E}}\left[i_{t}\right]+\hat{\theta}_{\pi}+\hat{\gamma} \hat{\theta}_{c}-\hat{\gamma} \hat{\eta} \hat{\sigma}_{c}^{2} \hat{\theta}_{c}+(1-\hat{\gamma} \hat{\rho}) \hat{\rho} \hat{\eta}\left(1-\hat{\phi}_{\epsilon}^{2}\right) \operatorname{vãr}\left(\pi_{t}^{t o t a l}\right) \hat{\theta}_{c} \\
& -\frac{1}{2} \hat{\gamma}^{2} \hat{\sigma}_{c}^{2}-\frac{1}{2}(1-\hat{\gamma} \hat{\rho})^{2}\left(1-\hat{\phi}_{\epsilon}^{2}\right) \operatorname{vãr}\left(\pi_{t}^{t o t a l}\right)
\end{aligned}
$$

The parameter value $\hat{\gamma}$ was set to 0.975 and $\hat{\eta}$ was set to match the slope of the curve. The value $\hat{\gamma}$ minimizes the difference between the volatility of the short-term rate in the data and the model. The parameter value for $\kappa$ was obtained from the monetary policy literature.

\section{Welfare-Improving Policies}

Consider the problem of finding $\pi_{t}$ and $x_{t}$ to minimize the stabilization component of the policy objective function in equation (25) subject to the aggregate supply equation (4) and restricting attention to policies were the equilibrium inflation and output gaps depend linearly on supply shocks.

Guess solutions of the form $\pi_{t}=\bar{\pi}+\pi_{\epsilon} \epsilon_{t}$ and $x_{t}=\bar{x}+x_{\epsilon} \epsilon_{t}$. In order to satisfy (4), it is necessary that

$$
\bar{\pi}=\frac{\kappa x^{*}}{1-\beta} \quad \text { and } \quad \pi_{\epsilon}=\frac{\kappa x_{\epsilon}+1}{1-\beta \phi_{\epsilon}} .
$$

Given this restrictions, the problem for the monetary authority can be written as

$$
\min _{\pi_{\epsilon}} \frac{1}{2}\left[\pi_{\epsilon}^{2}+\frac{1}{\kappa \rho}\left(\left(1-\beta \phi_{\epsilon}\right) \pi_{\epsilon}-1\right)^{2}\right] \sum_{t=0}^{\infty} \beta^{t} \operatorname{var}\left(\epsilon_{t}\right) .
$$

Solving this optimization problem it follows that

$$
\pi_{\epsilon}=\frac{1}{1-\beta \phi_{\epsilon}+\frac{\kappa \rho}{\left(1-\beta \phi_{\epsilon}\right)}}=\frac{1}{1-\beta \phi_{\epsilon}+\kappa \rho_{r c}} .
$$

From the restrictions above, the equilibrium output gap is found and the targeting rule follows. 


\section{Additional Figures}

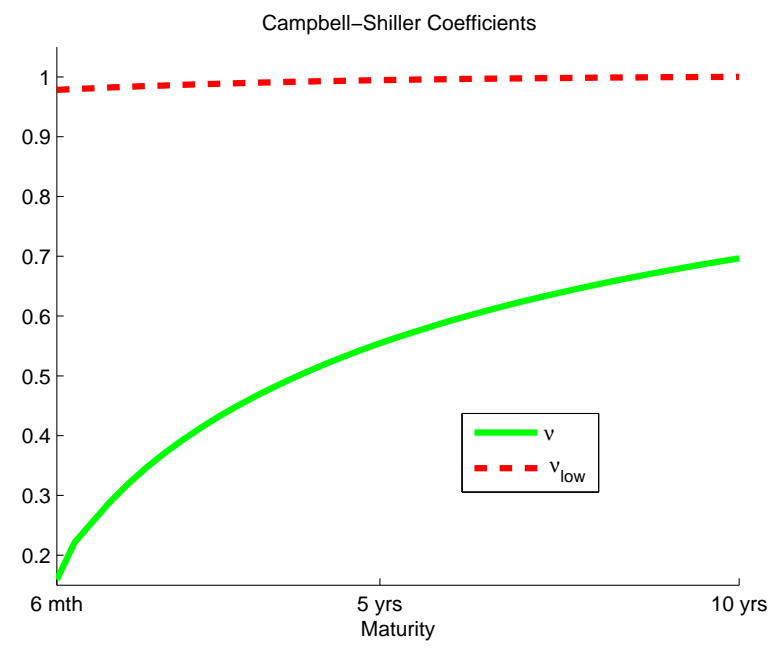

Figure 10: Model-implied Campbell-Shiller coefficients.

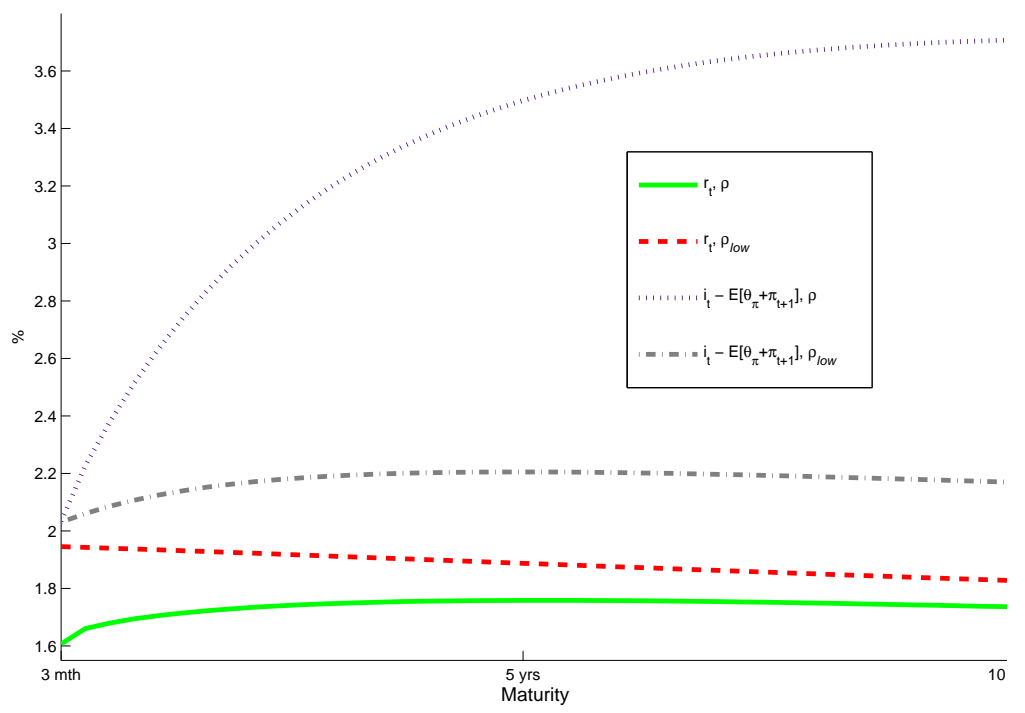

Figure 11: Real Interest Rates and Difference $\mathbb{E}\left[i_{t}\right]-\mathbb{E}\left[r_{t}+\theta_{\pi}+\pi_{t+1}\right]$.. 

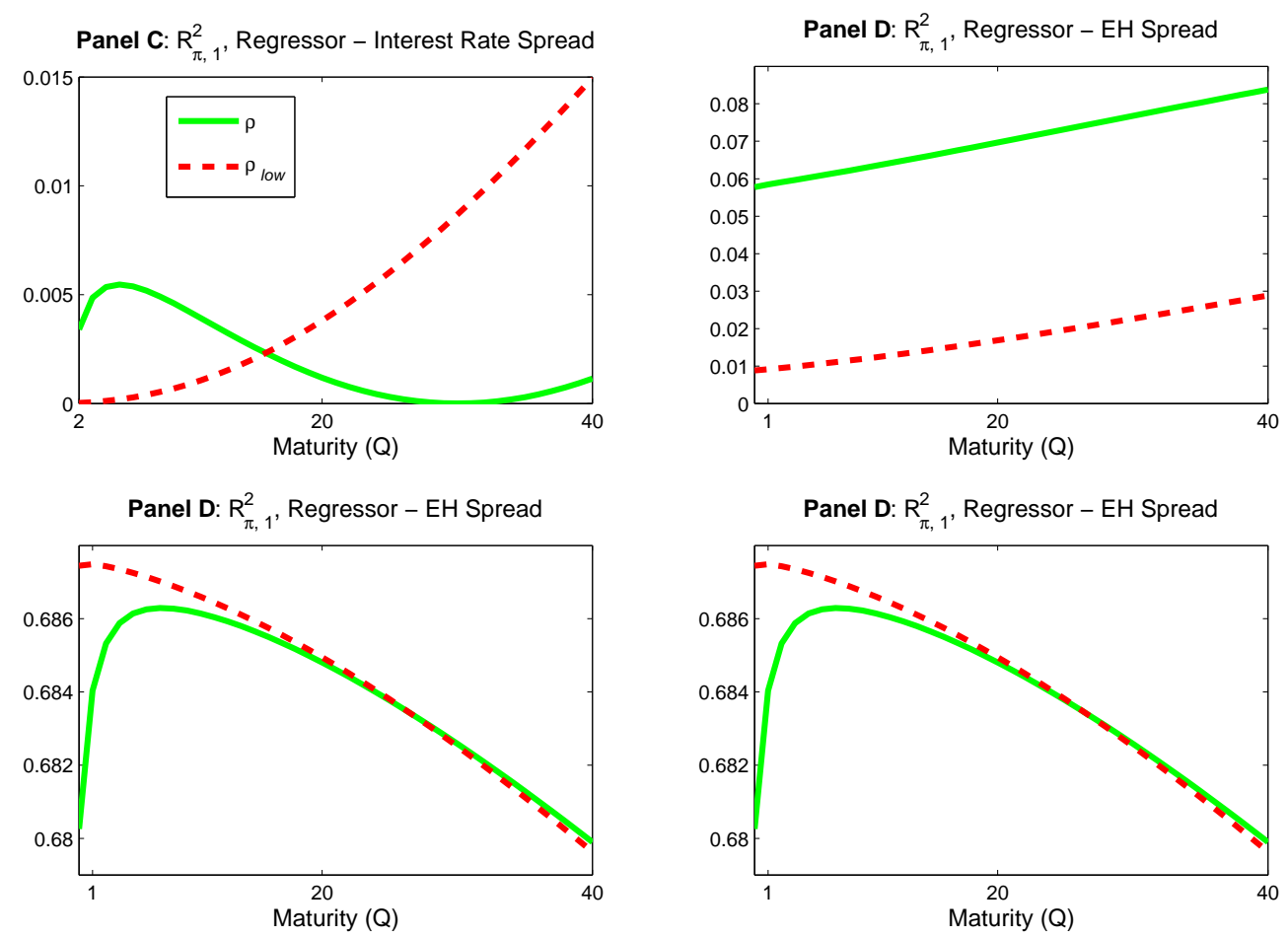

Figure 12: $\quad R^{2}$ 's for univariate regressions $m v_{t+1}=\alpha_{m v, 1}+\beta_{m v, 1}\left(i_{t}^{(n)}-i_{t}\right)+\varepsilon_{m v, 1}$, for $m v=$ $\{\Delta c, \pi\}$. The regressor is the interest rate spread or its expectations hypothesis component for different maturities. 